\title{
Assessing TBM performance in heterogeneous rock masses
}

\author{
Sarah Sissins ${ }^{1} \cdot$ Chrysothemis Paraskevopoulou $^{1}$ (D)
}

Received: 22 July 2020 / Accepted: 16 March 2021 / Published online: 21 June 2021

(C) The Author(s) 2021

\begin{abstract}
A major challenge that TBM performance is requested to deal with for a successful and effective progress is tunnelling through lithologically and geomechanically heterogeneous rock masses. Such heterogeneous environments are common and recent tunnel examples in the UK include the Hinckley Point $C$ offshore cooling tunnels being driven through interbedded carbonaceous mudstone/shales and argillaceous limestone and the Anglo American's Woodsmith Mine Mineral Transport System tunnel in Redcar Mudstone with beds of ironstone. This inherent geological heterogeneity leads to difficult tunnelling conditions that initially stem from predicting a sound and representative ground model that can be used to preliminary assess the TBM performance. In this work, an exhaustive review of existing TBM Penetration Rate (PR) methods identified that no models address the issue of parameter selection for heterogeneous rock masses comprising layers with different rock strengths. Consequently, new approaches are required for estimating rock mass behaviour and machine performance in such environments. In the presented work the Blue Lias Formation (BLI), which is characterised by its layered rock mass, comprising very strong limestone, interbedded with weak mudstone and shales, is investigated. BLI formation is considered herein being a representative example of lithological heterogeneity. Based on the fieldwork carried out in three localities in the Bristol Channel Basin (S. Wales and Somerset), geological models are produced based on which a geotechnical model is developed, and four ground types are determined. Implications of the current findings for TBM performance are assessed, including faulting, groundwater inflow and excavation stability with a particular focus on both PR and advance rate. A modified approach using the existing empirical models is proposed, developed and presented in this paper that can be used as a guide to determine TBM performance in heterogeneous rock masses reducing the risk of cost and time overruns.
\end{abstract}

Keywords Heterogeneous rock masses $\cdot$ TBM performance $\cdot$ TBM penetration rate and advance rate $\cdot$ Utilisation index

\section{Introduction}

Tunnelling through heterogeneous rock masses is a major challenge that can impact the tunnel advancement significantly especially in the case of mechanised tunnelling (TBM). TBMs are usually selected for specific ground conditions and unexpected variances within the ground model and its mechanical behaviour, for instance, reduction in rock mass quality through faulting and folding or through lithological variation can lead to increased downtime, delivery delays and overall progress rates. Accurately predicting rock behaviour is paramount to the success of tunnelling projects;

Chrysothemis Paraskevopoulou c.paraskevopoulou@leeds.ac.uk

1 School of Earth and Environment, University of Leeds, Leeds, UK mistakes adversely affect both time and costs (Paraskevopoulou and Benardos 2012, 2013; Benardos et al. 2013; Bilgin et al. 2014; Paraskevopoulou and Boutsis 2020). A broad range of empirical models have been introduced to predict TBM performance. These are typically based on specific sites, geology and/or limited data, often leading to inaccurate predictions; especially when used outside their original applications and without good judgement.

It should be stated that in this paper, the heterogeneity is considered to be from the natural lithological variations in stratigraphic sequences using as a case study the Blue Lias Formation (BLI) formation of the Bristol Channel Basin (BCB) (Fig. 1). The Blue Lias Formation (BLI), as a result of fluctuating shallow seas, is characterised by its layered rock mass, comprising very strong limestone, interbedded with weak mudstone and shale layers (Hobbs et al. 2012). BLI is a representative rock mass when considering heterogeneity and for this purpose, the BLI is investigated in this study. 
Fig. 1 Distribution of the Lias Group and position of field localities (modified Simms et al. 2004; BGS 2019)

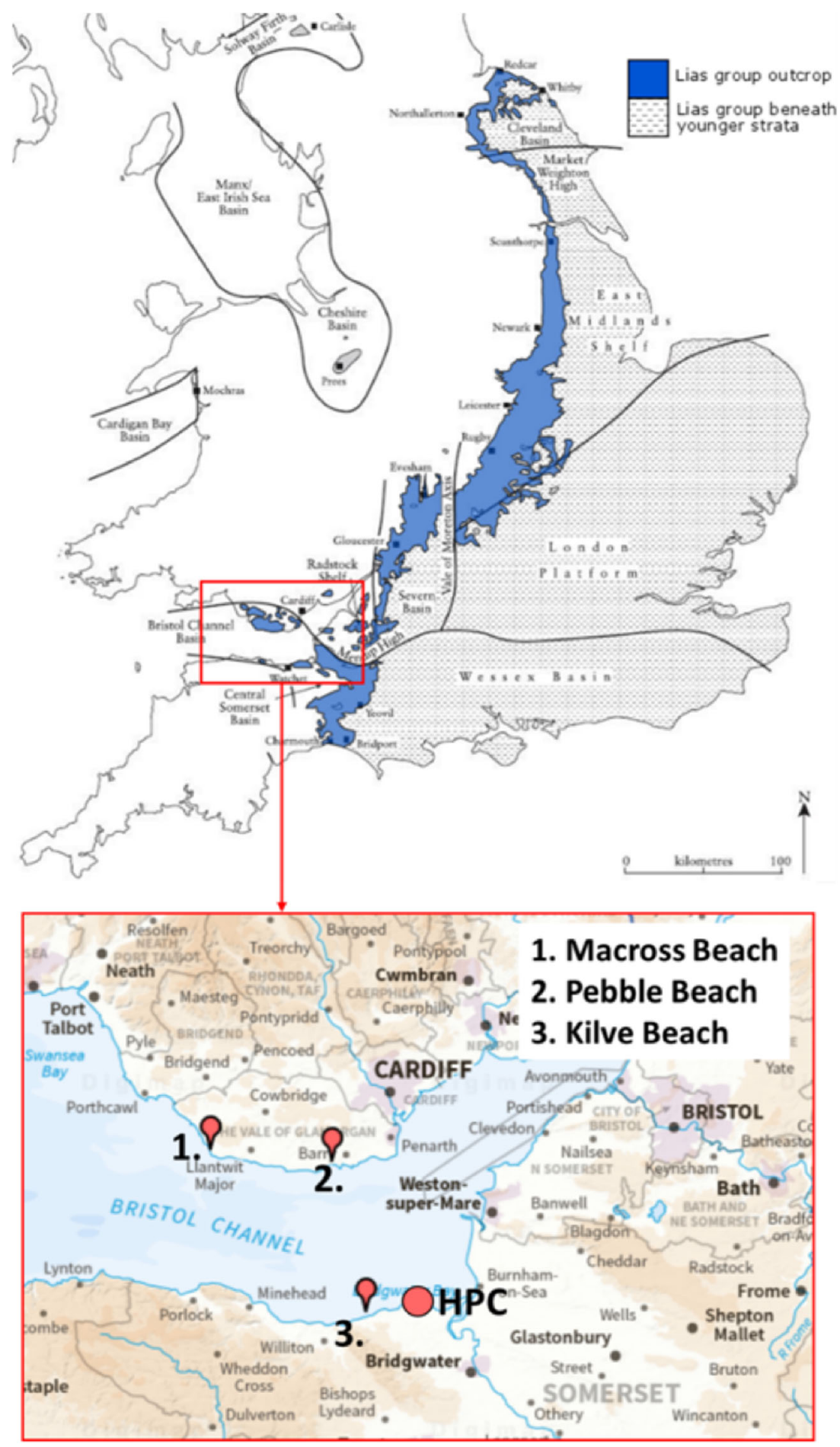

BLI's layering of limestone and mudstone/shale results in heterogeneous tunnelling conditions whilst directly hindering sound ground behaviour predictions and thus TBM performance which few empirical models currently address.

It is evident that a new approach/methodology is required for estimating machine performance in heterogeneous materials based on the overall rock mass behaviour. It is also common that available borehole data is often sparse and inadequate. Hence, it is common, practicable and often necessary, to compile predictions using only desk study information and field reconnaissance at least at the preliminary design stages of a tunnelling project. The latter forms the basis of this research work in which the rock mass is characterised by evaluating geotechnical properties and mechanical behaviour based on fieldwork observations and laboratory testing results. This research also addresses critical controls on the TBM 
performance and provides a comprehensive review of relevant models; compared to produce accurate performance estimations within the BLI. It is shown in the following sections that the Hassanpour et al. 2009 model gives better results in such heterogeneous environments. The aim of this paper is to propose a modified approach for predicting TBM performance in heterogeneous environments based on existing empirical models using primary collection datasets from field observations, in situ and lab testing.

\section{The site and geology}

Although several sites show natural lithological variations in stratigraphic sequences, the BLI which is exposed on the north and south shore of the BCB is selected in this research work (Fig. 2a). A desk study of published data of the BCB is completed, including review of reports, memoirs, satellite and geological maps aiming at developing a conceptual geological model and evaluate the rock mass behaviour with regard to TBM performance. It should be noted that field work was intentionally conducted to create an original dataset that can be further analysed to determine the geotechnical model.

\section{Geological setting}

The BCB is an exhumed fault-bounded graben, which developed in the early Mesozoic due to gradual rift-related subsidence. The basement rock consists of Devonian Old Red Sandstone and Carboniferous Limestone. This is overlain by Triassic (Mercia Mudstone Group and Penarth Group) and Early Jurassic (Lias Group) basin-fill deposits, of up to $2.25 \mathrm{~km}$ in thickness. The Lias Group was deposited in warm, shallow seas, similar to the modern Mediterranean. The Jurassic, basin subsidence and marine deposition occurred at similar rates, maintaining shallow water depth and building up the thick succession of the Lias Group. Sea-level fluctuations resulted in limestone interbedded with calcareous shale and mudstones. Within the $\mathrm{BCB}$, a major difference in geological history between $\mathrm{S}$. Wales and Somerset is the weathering domains, controlled by the extent of glaciation and peri glaciation (Hobbs et al. 2012).

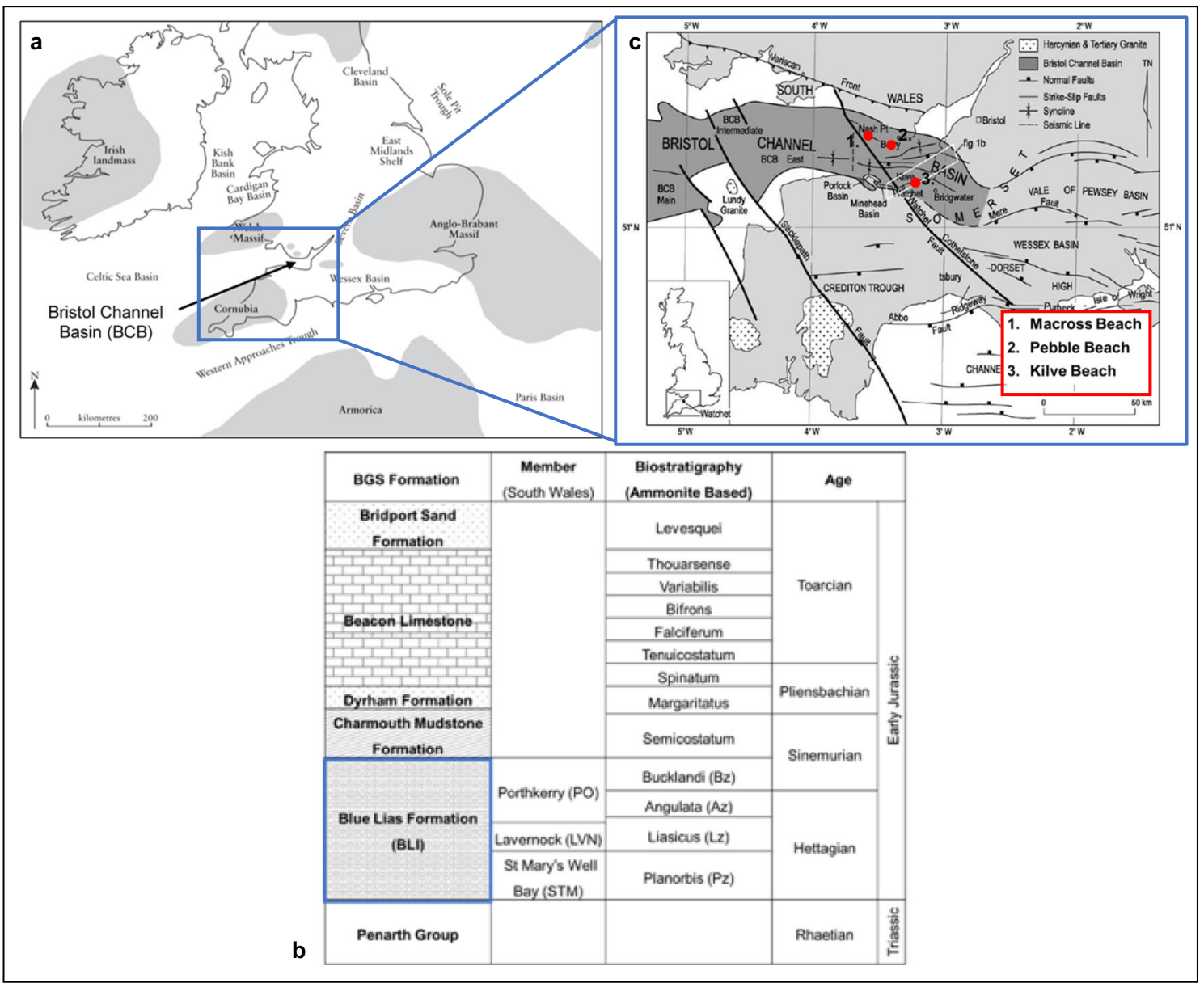

Fig. 2 a. Lower Jurassic palaeogeography (modified after Simms et al. 2004); b. Stratigraphy of the Lias group in the BCB (modified after Cox et al. (1999) and Simms et al. (2004)); and, c. Main structure of the BCB (modified after Glen et al. 2005). 
Table 1 Summary of penetration rate (PR) models

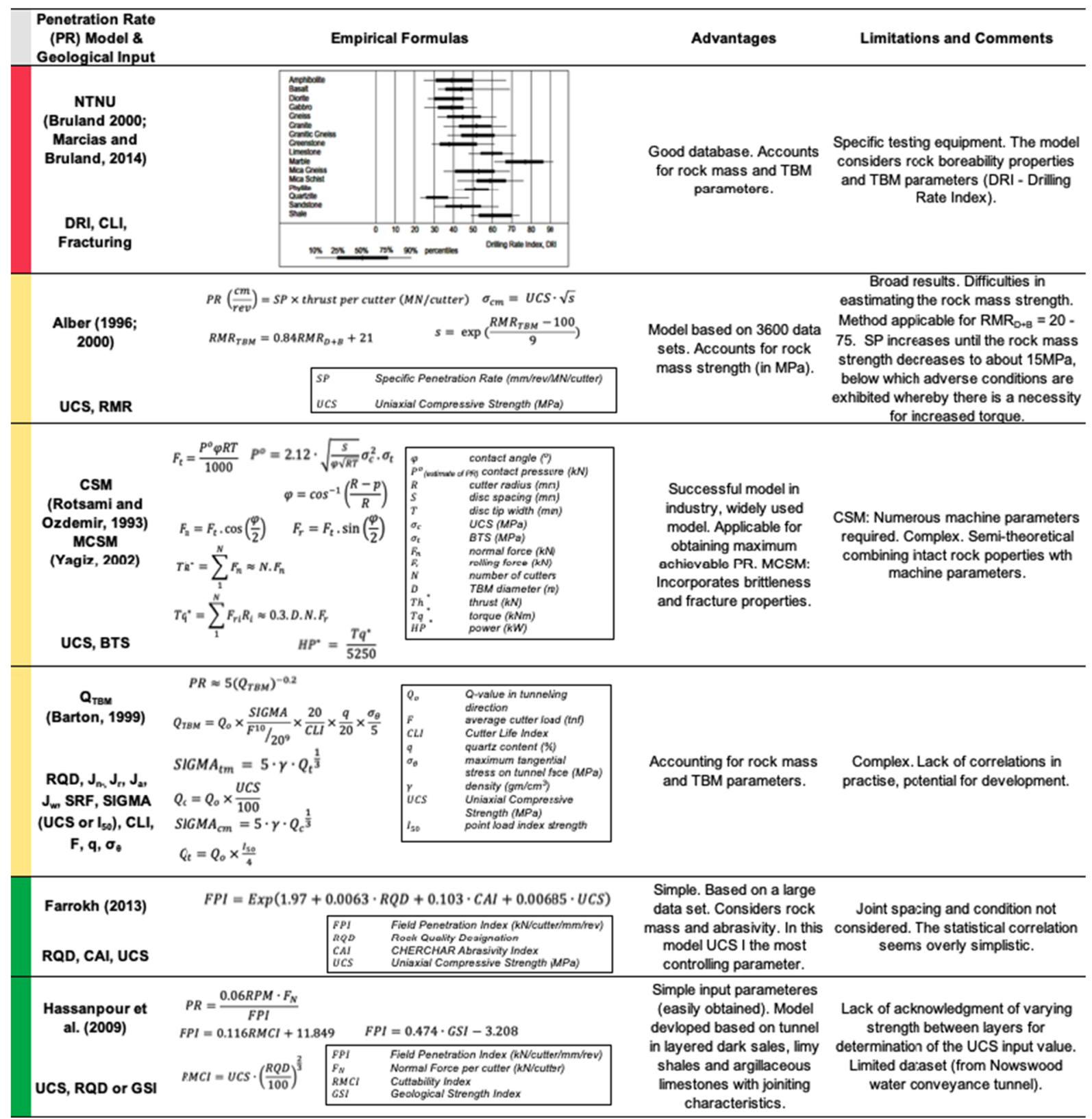

The stratigraphy of the BCB Lias Group, summarised in Fig. 2a, has been investigated by numerous authors. Cox et al. (1999) introduced a lithostratigraphic framework, advising formational nomenclature as opposed to division into Lower, Middle and Upper. The Blue Lias previously formed part of the 'Lower Lias' along with the overlying Charmouth Mudstone. Whittaker and Green (1983), amongst others, present a detailed lithostratigraphy of the Somerset Lias Group. BGS (2019) defines the top of the Blue Lias to be 'Bed 238' by Whittaker and Green and is associated with a notable decrease in limestone beds. The S. Wales coast is less well documented but works include Sheppard et al. (2006). The Lias
Group is highly fossiliferous including abundant ammonites, allowing sub-division into biostratigraphic zones, the BLI consists of the Bucklandi Zone (Bz), Angulata Zone (Az), Liasicus Zone $(\mathrm{Lz})$ and Planorbis Zone $(\mathrm{Pz})$. For S. Wales, the BLI is best divided into three distinct members (Fig. 2b); whilst for Somerset, no such members exist (Hobbs et al. 2012). For reporting purposes, the Bz of Somerset observed during fieldwork is hereby named SS Member.

The deformation history of the $\mathrm{BCB}$ is complex, dominated by NW trending strike--slip faults and E to ENE trending faults and folds; including the regional Bristol Channel Syncline (Fig. 2c). Normal faults formed as a result of $\mathrm{N}-\mathrm{S}$ extension 
Table 2 Rock engineering description

\begin{tabular}{|c|c|c|}
\hline \multicolumn{3}{|c|}{ Summary of field rock descriptions } \\
\hline Lithology & Limestone & Mudstone/shale \\
\hline Description & $\begin{array}{l}\text { Very strong to strong, thinly } \\
\text { to thickly bedded, } \\
\text { medium grey } \\
\text { LIMESTONE. With } \\
\text { common fossils } \\
\text { (including ammonites). } \\
\text { Weathers light grey, } \\
\text { common orange staining } \\
\text { often confined to } \\
\text { discontinuities. }\end{array}$ & $\begin{array}{l}\text { Extremely weak to medium } \\
\text { strong, thinly laminated, } \\
\text { thinly to thickly bedded, } \\
\text { dark grey MUDSTONE. } \\
\text { With common fossils. } \\
\text { Weathers orange in } \\
\text { places. }\end{array}$ \\
\hline
\end{tabular}

Full Engineering Geological Description for Each Member observed (the limestone and mudstone across localities are similar).

$\begin{array}{lc}\text { Locality } & \text { Limestone } \\ 1 & \text { Very strong, thinly to } \\ \text { (S.Wale- } & \text { medium bedded, medium } \\ \text { s) } & \text { grey LIMESTONE. Blue } \\ & \text { Lias Formation } \\ & \text { (Porthkerry Member). } \\ & \text { Weathers light grey on } \\ & \text { surface and often orange } \\ & \text { staining on surface, } \\ & \text { occasionally orange } \\ & \text { staining is confined to } \\ & \text { discontinuities. } \\ & \text { Very strong, thinly to } \\ \text { (S. } & \text { medium bedded, light to } \\ \text { Wales) } & \text { medium grey, } \\ & \text { LIMESTONE. Blue Lias } \\ & \text { Formation (Lavernock } \\ & \text { Shale Member). Weathers } \\ & \text { light grey on surface. }\end{array}$

2 (S. Very strong, thinly to

Wales) medium bedded, light to medium grey,

LIMESTONE. With

frequent fossils (shelly including ammonites).

Blue Lias Formation (St Mary's Well Bay

Member). Weathers light

grey on surface. Some

orange staining primarily

along discontinuities.

$3 \quad$ Very strong to strong, thinly

(Somer- to medium bedded,

set) medium grey with pale

grey speckles,

LIMESTONE. With

common fossils

(including ammonites).

Blue Lias Formation (SS

Member - Bucklandi

Zone). Weathers pale grey

on surface and occasion-

ally brown-orange.

Very weak to medium strong, thinly laminated, medium to dark grey MUDSTONE. Blue Lias Formation (Porthkerry Member). Weathers orange in places. during the Late Jurassic, later followed by basin inversion, including both $\mathrm{N}-\mathrm{S}$ and $\mathrm{E}-\mathrm{W}$ contraction, resulting in numerous overprinting relationships and reactivated faulting (Glen et al. 2005). Most faults are planar normal faults, with some bedding-parallel faults and extensional shear zones. Bedding is highly persistent and dips north by $10-12^{\circ}$ in the southern BCB. Vertical to sub-vertical joints are common with high frequency, 3-4 joints per $\mathrm{m}$, within the limestone bands, oriented $\mathrm{E}-\mathrm{W}, \mathrm{N}-\mathrm{S}$ or $\mathrm{S}-\mathrm{W}$. At depth, joints are predominantly tight and frequently infilled with calcite or gypsum deposits (Royal Haskoning 2009). According to Glen et al. (2005), the nature of folding and fracturing is controlled by the dominance of limestone beds, demonstrating the importance of the limestone-mudstone ratio investigated in this research work.

\section{Tunnelling through BLI, considerations and ground behaviour}

In this project research, a hypothetical mechanised tunnel is assumed to be excavated in the afore-described geological setting and an Earth Pressure Balance Machine (EPBM) is selected as it is applicable for the following conditions: soft ground, or if high water pressures and/or variable ground conditions are expected. EPBMs incorporate scrapers and/or disc cutters and can operate in open/closed mode. Important factors such as ground behaviour characterisation, groundwater conditions and faulting must be considered, with reference to their effect on TBM performance.

Rock mass classification systems are important as the behaviour of a rock mass is considered to be governed considerably more by discontinuities than the strength of the intact rock (Palmström 2001). They are generally empirical correlations, relating quantifiable rock mass properties and observed mechanical behaviour during excavations. The most widely used systems are Rock Mass Rating or RMR (Bieniawski 1973); Rock Tunnelling Quality Index or Q-System (Barton et al. 1974); and Geological Strength Index or GSI (Hoek et al. 1992). RQD was developed to provide a quantitative estimate of rock mass quality from drill logs (Deere and Deere 1988). An advantage of the GSI system is that it provides a field method for characterising rock masses, by basic geological observations (Marinos et al. 2005). It should be highlighted outcrops, although an extremely valuable data source, are susceptible to surface relaxation, weathering and alteration, which needs consideration when assessing the likely GSI values at depth (Sattler and Paraskevopoulou 2019). Marinos and Hoek (2001) developed extensions for heterogeneous and lithologically varied sedimentary rock masses, similar to the BLI and later advanced by Marinos (2019).

The Advance Rate (AR) is a measure of excavation speed, or distance bored divided by the total time taken (distance/ time) and is extremely important in terms of total project costs 
Fig. 3 S. Wales members (Locality 2)
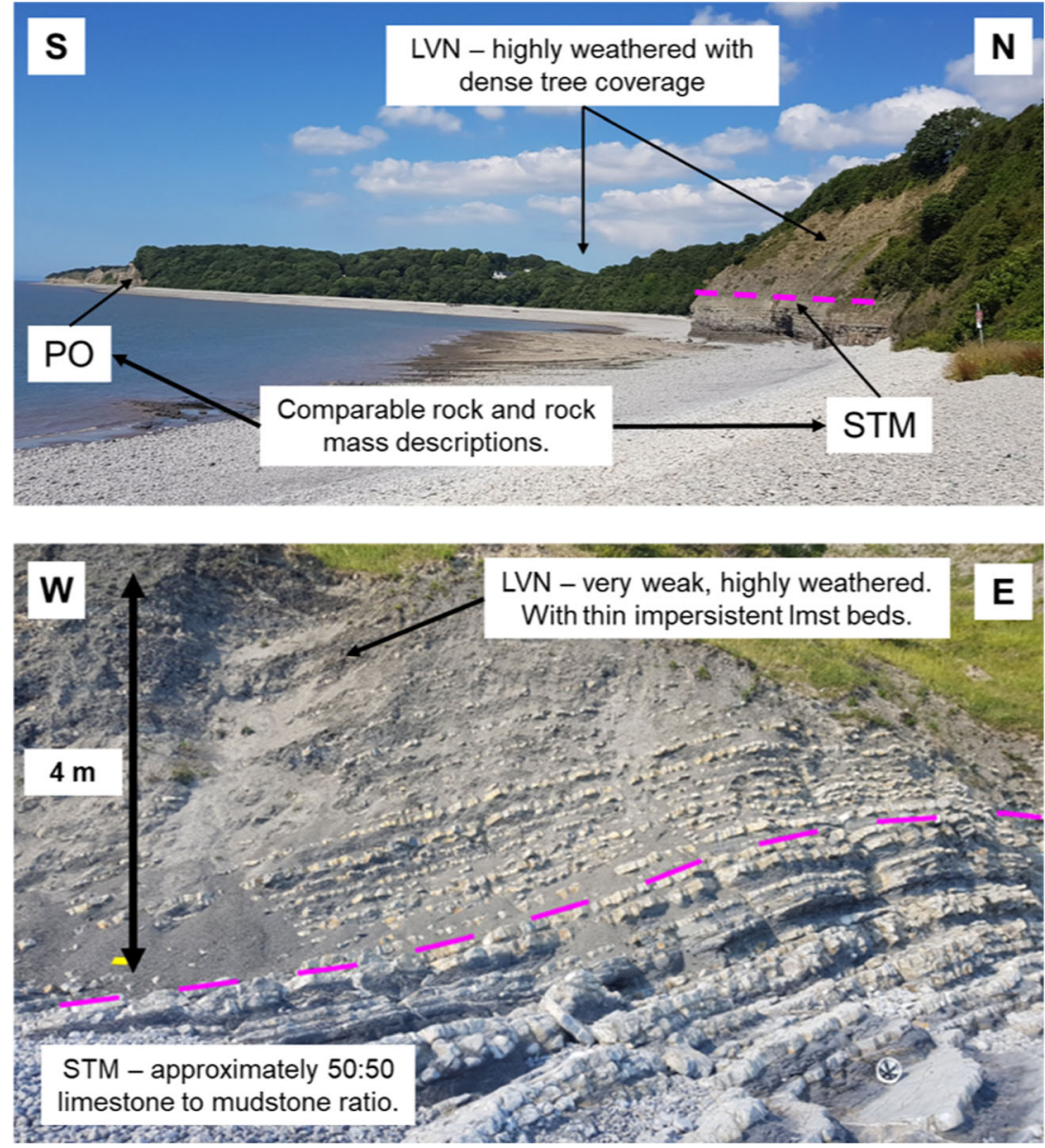
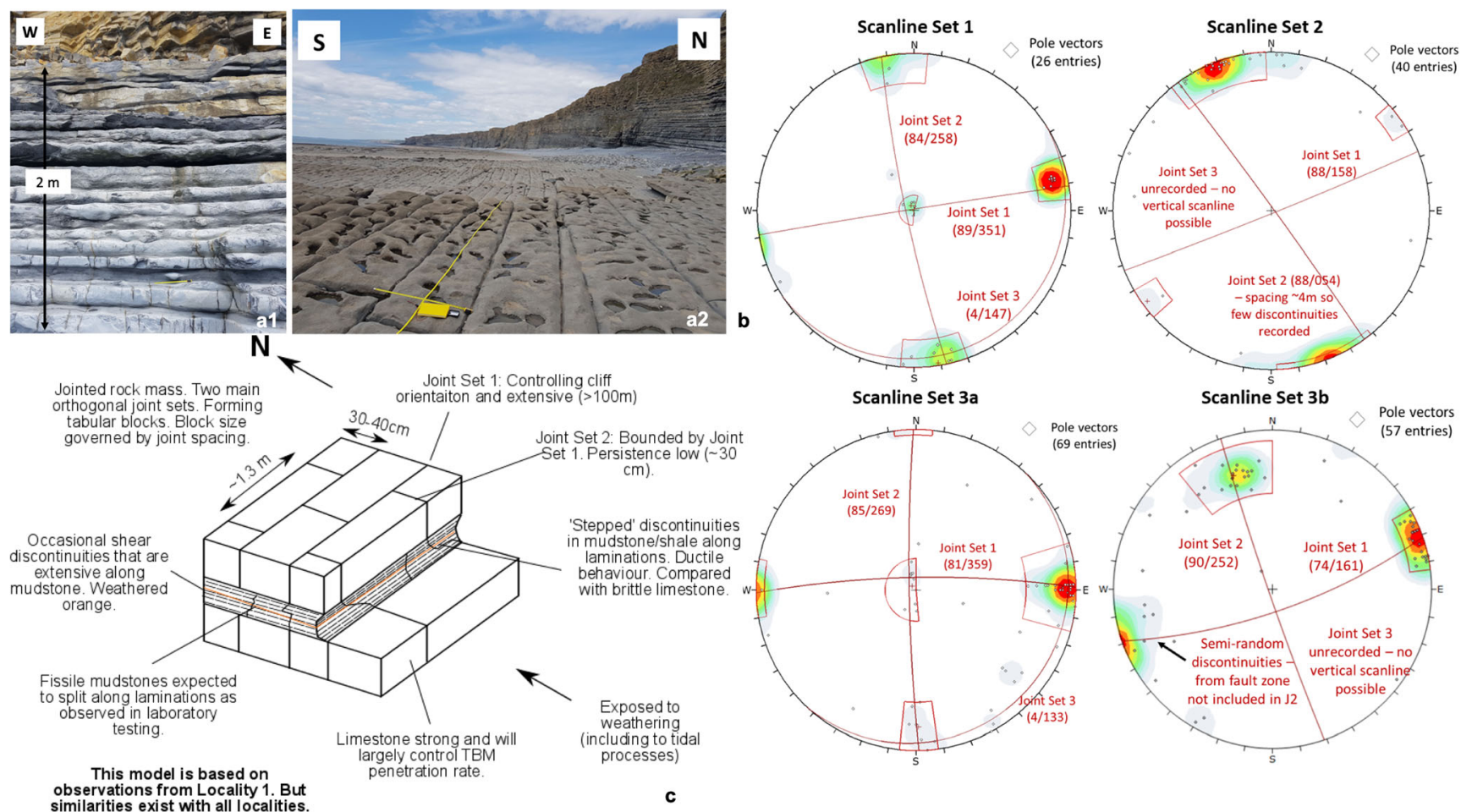
observations from Locality 1 . But
similarities exist with all local ities.

Fig. 4 a. Set up for Scanlines, b. Discontinuity stereonets, c. Block diagram of discontinuities based on Locality 1 
and time estimates. AR is fundamentally twofold and can be divided into mining/excavating and support as shown in the following equation by Barton (1999):

Advance Rate $(A R)=$ Penetration Rate $(P R) \times \operatorname{Utilisation}(U)$

where PR is the instantaneous penetration rate or distance mined during continuous boring $(\mathrm{m} / \mathrm{h})$ and $\mathrm{U}$ is the percentage of shift time that excavation occurs $(\%)$.

$\mathrm{AR}$ varies significantly, with the world record performance for long-distance tunnel drives being $2 \mathrm{~m} / \mathrm{h}$ (over a period of 1 year). Typical advance rates for 6-10 $\mathrm{m}$ diameter TBMs is around 1.1 $\mathrm{m} / \mathrm{h}$ (Barton 2014). The Crossrail EPB TBM AR ranged between 0.5 and $1.1 \mathrm{~m} / \mathrm{h}$ (Kenyon, 2015). In terms of PR, typically this does not exceed $5 \mathrm{~m} / \mathrm{h}$ in practice, meaning calculated values higher than this are largely theoretical (Barton 2000). The lack of sufficient face pressure may result in face instabilities, despite stabilising pressure provided by EPB machines. Stability is controlled by regulation of the screw rotation and AR to manage face pressures (Anagnostou and Kovári 1996).

The PR prediction models can be categorised as: (i) empirical, based on field studies and data from TBM tunnelling; and, (ii) theoretical, based on laboratory tests. Due to the lack of access to required rock cutting laboratory tests, the empirical models are considered herein. Early models, circa the 1970s, were simple incorporating only single parameters, commonly the Uniaxial Compressive Strength or the tensile strength which were related to the cutter force e.g. Farmer and Glossop (1980). Over time, models expanded to incorporate a wider variety of input parameters, RQD, abrasivity, joint spacing etc. (Farrokh et al. 2012) which implies the difficulty in estimating performance. In hard rock, PR is limited by cuttability i.e. force required to break the rock provided by the cutter load (Gong and Zhao 2009). It is widely accepted that the intact rock strength (UCS) has a critical role. PR is also governed by the interaction between the machine parameters (torque, thrust and machine power) and the rock mass parameters (rock strength, joints, fractures, brittleness). Generally, discontinuities reduce the rock mass strength to a fraction of the intact strength. Predictions of PR that rely solely on intact rock strength are not representative of the in situ conditions (Alber 2000). Table 1 summarises the different models used for estimating PR. It should be noted that the results from different models are based on different geological conditions and/or machine specifications, which makes it challenging for comparison and can lead to misleading conclusions when used beyond their original applications. Given the fractured nature of the BLI, methods that incorporate rock mass characteristics, GSI (Flysch), should be preferred. Only a few models have been developed for tunnels in mixed-face ground conditions e.g. Vergara and Saroglou (2017) which are mostly based on granites. Alber (1996) mentions that heterogeneous-layered conditions may cause differential penetration of the discs, vibrations and disc damage, but does not propose a solution for managing these conditions. Tarkoy (2009) suggests that the anticipated PR for the most resistant material in the face can be used, likely resulting in considerable underestimates. Diederichs (2020) highlights that sedimentary or volcaniclastic layering creates challenges for tunnelling if not considered during the design stage as the anisotropic response is not directly taken into account in the common analysis methods. It should be noted, in this presented work that the model developed by Hassanpour et al. (2009) is the most relevant as it was developed based on dark shales, limy shales and argillaceous limestones with jointing characteristics similar to the BLI and regional structures analogous to the BCB. The afore scribed implies that a methodology for predicting TBM performance when dealing with heterogeneous rock masses similar to Flysch and BLI whilst using these empirical models is required. Such methodology is presented in the following sections.

Utilisation (U) is affected by numerous factors e.g. rock mass characteristics, site conditions, TBM limitations and downtime (Alber 1996). Where poor-quality rock is encountered, high PR may be possible but AR will be low due to support requirements (and operator reduced PR). Ucoefficients could be as low as 5-10\% (Sapigni et al. 2002). Alber (2000) presents a model correlating Factor of Safety (FS) and U. Barton (2000) proposed that, for time (T),

Utilisation $=T^{m}$

where $\mathrm{m}$ is negative to account for decay in $\mathrm{U}$ over time, normally taken as -0.2 , but varies according to conditions. The Rock Mass Excavability (RME) model can be used to determine TBM AR; however, Drilling Rate Index (DRI) is required.

\section{Site investigation and fieldwork}

Given the absence of borehole data, a detailed site investigation was carried out involving field testing and sampling in July 2019. This enabled primary data collection from field observation and testing that was used to create both the ground (geological) and the geotechnical models presented in this work. The derived parameters were also used as input data for the empirical models previously described. The three localities under investigation selected are shown in Fig. 1, covering representative sections, based on accessibility and apparent exposure assessed from literature and aerial maps. The main activities during the fieldwork are summarised in Table 10.

\section{Rock descriptions}

Table 2 summarises the rock descriptions derived from the site investigation. They mainly comprise interbedded argillaceous 
and Carboniferous mudstone/shales with different mechanical characteristics. The thickness and ratio of beds varies considerably between members. The SS Member (Somerset) comprises very prominent mudstone beds, the Porthkerry (PO) and St Mary's Well Bay (STM) members (S. Wales) are broadly similar, containing an equal bed ratio. However, the
Lavernock Shale (LVN) member is fissile weathering to low slope angles likely resulting from the low limestone content, although, at depth, it is expected that the unit will be more massive. From Locality 2, the three S. Wales members of the BLI are clearly observed Fig. 3.
Fig. 5 Faulting (a) Locality 1; (b) Locality 2; and, (c) Locality 3
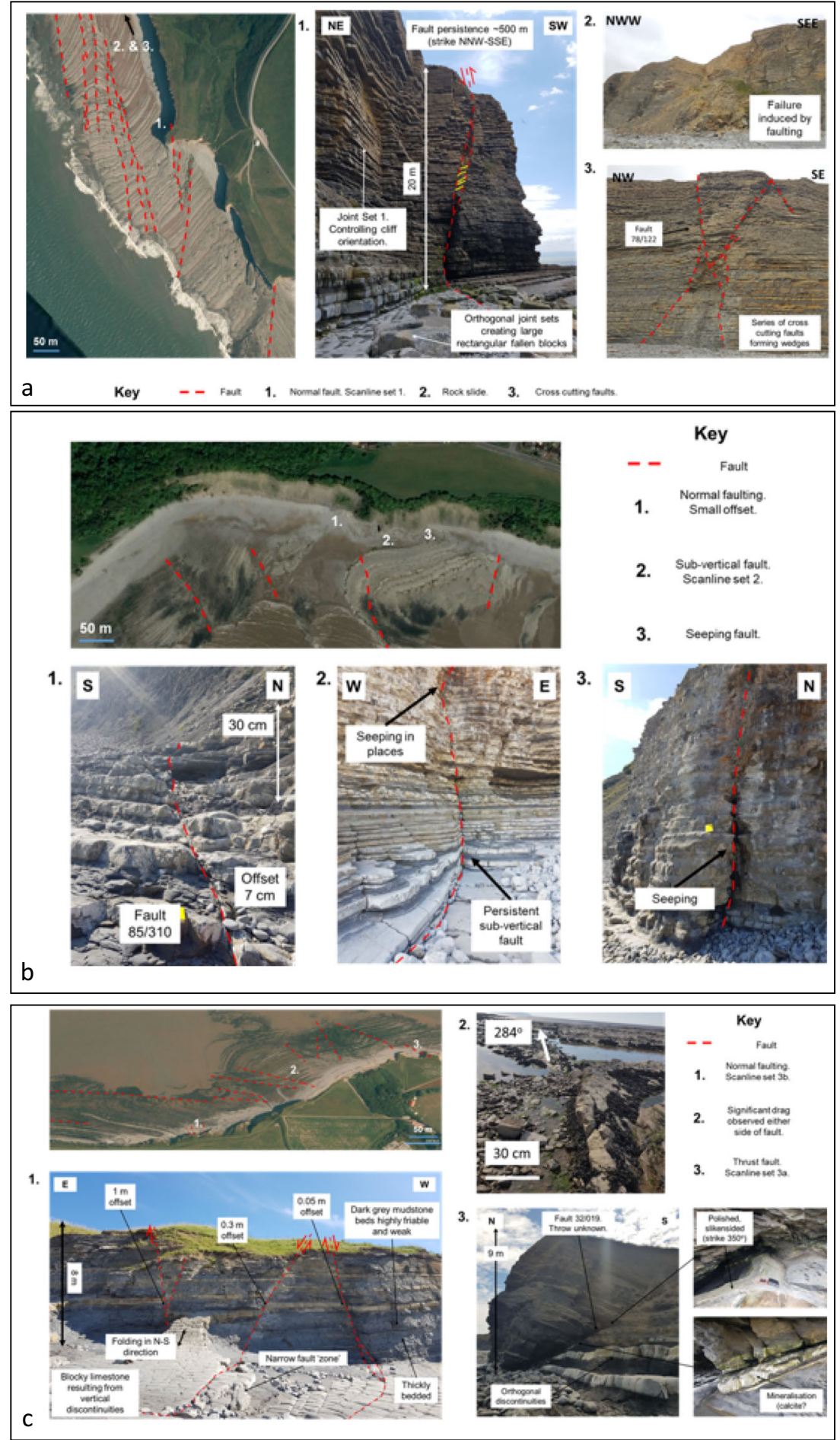
Table 3 Summary of rock mass classification investigations

\begin{tabular}{llllll}
\hline Locality & Member & GSI & RMR & Q & RQD (\%) \\
\hline 1 & PO & $44-54$ & $55[48-67]$ & $1.9[0.59-4.4]$ & $80-100$ \\
& & & Fair & Poor & \\
& LVN & $25-35$ & n/a & n/a & $0-20$ \\
2 & STM & $44-54$ & $55[48-67]$ & $1.9[0.59-4.4]$ & $80-100$ \\
& & & Fair & Poor & \\
3 & SS & $35-48$ & $54[44-67]$ & $1.8[0.50-4.3]$ & $68-97$ \\
& & & Fair & Poor & \\
\hline
\end{tabular}

\section{Discontinuities surveys, scanlines and structure}

An example scanline set-up is shown in Fig. 4a. Table 11 and Fig. $4 \mathrm{~b}$ summarise the scanline discontinuity data. Scanlines were recorded in three dimensions and greater than $3 \mathrm{~m}$ were completed in places, to incorporate discontinuities with larger spacings as at depth these large-scale discontinuities are likely to be present. For all localities, three discontinuity sets (plus random) were observed. The joint sets broadly correlate between localities and express similar jointing characteristics. Joint Set 1 (J1) discontinuities are E-W oriented, vertical and highly persistent. J2 discontinuities are also vertical striking approximately $\mathrm{N}-\mathrm{S}$ so are orthogonal to and bounded by J1, resulting in low horizontal persistence. $\mathrm{J} 3$ discontinuities only occur in the mudstone, they are sub-horizontal, including highly persistent bedding fractures and shear zones, often stained orange (indicative of water flow). For example, the discontinuities were observed at Locality 1, shown in Fig. 4c where they are more systematic with greater spacing in the limestone layers, creating a blocky appearance. The subvertical joints are often 'stepped' in the mudstone. Foliation and bedding planes also act as discontinuities, in terms of controlling failure. Within the fault zones, joints are more random and with higher frequency, but affected zones are often small $\sim 0.5 \mathrm{~m}$ (up to $4 \mathrm{~m}$ ).

Joint sets broadly correlate across localities, with differences in orientations attributed to local folding and faulting. The shallow dip angle $\left(70^{\circ}\right)$ for $\mathrm{J} 1$ (Joint set $3 \mathrm{~b}$ ), results from rotation by an obvious N-S fold. Discontinuities appear accountable for failure mechanisms and cliff stability e.g. J1 (a)

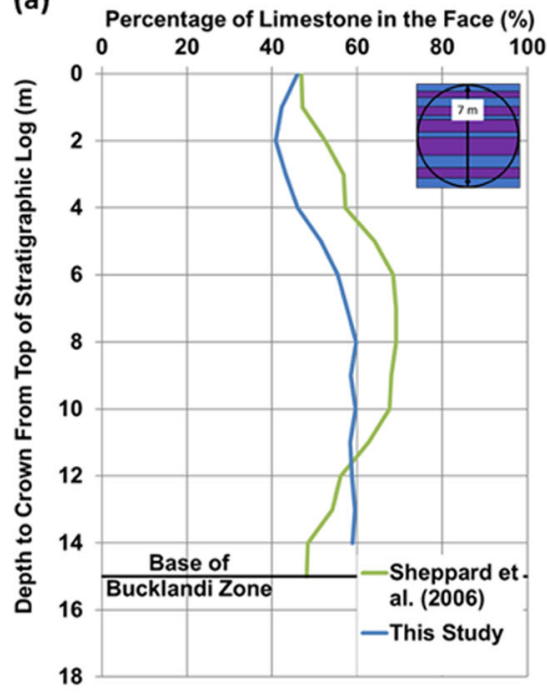

(d)

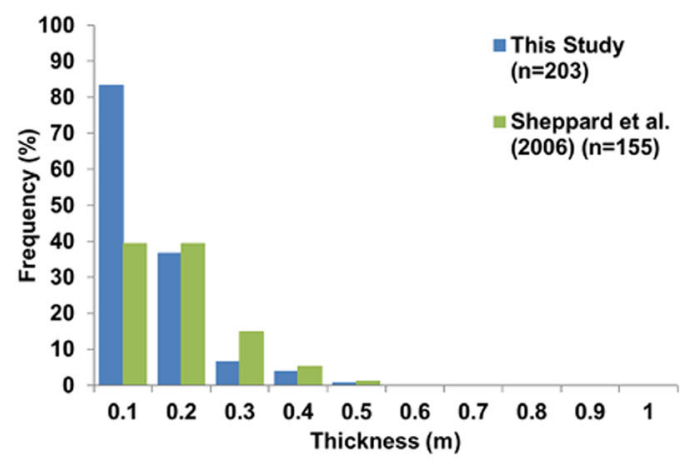

(b)

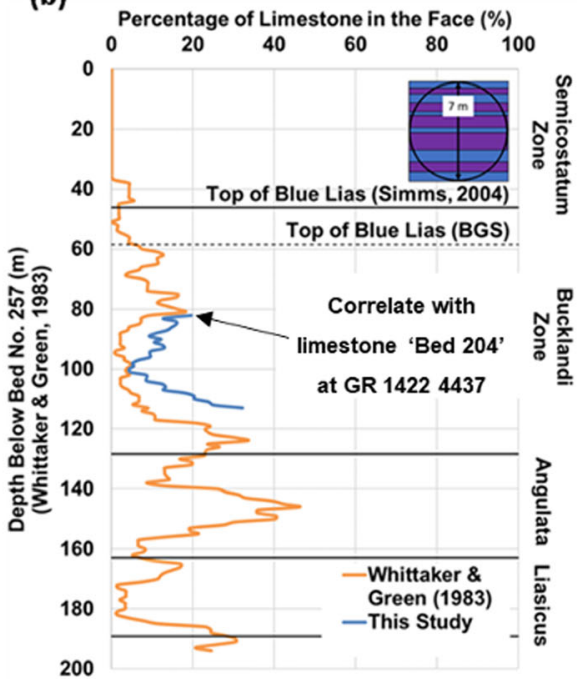

(c)

Percentage of Limestone in the Face (\%)

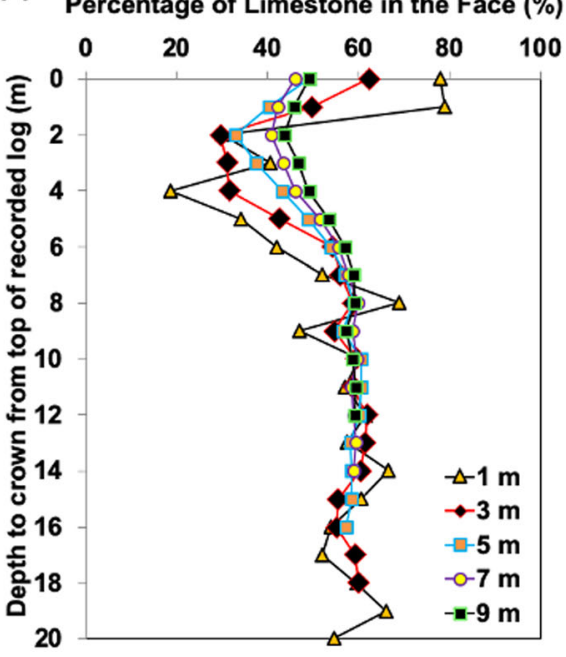

(e)

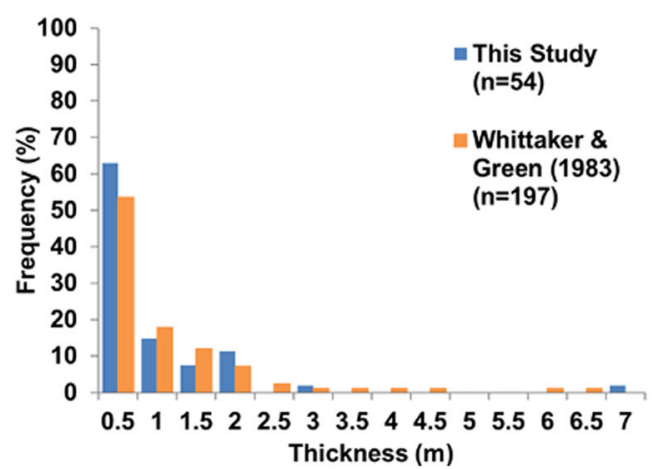

Fig. 6 (a) Percentage limestone (a) PO member (Locality 1); (b) Somerset coast, including SS Member (Locality 3); and, (c) Size effect on limestone percentage. PO member (for this study); Bed thickness (d) PO member (Locality 1); (c) Somerset, including SS Member (Locality 3) 
Table 4 Schmidt Hammer field work measurements and strength results

\begin{tabular}{|c|c|c|c|c|c|c|c|c|}
\hline \multirow[t]{2}{*}{ Locality } & \multirow[t]{2}{*}{ Member } & \multirow{2}{*}{$\begin{array}{l}\text { Orientation wrt } \\
\text { laminations }\end{array}$} & \multirow[t]{2}{*}{ Count } & \multicolumn{4}{|c|}{$\mathrm{R}$ values (Normalised to horizontal) } & \multirow[t]{2}{*}{ UCS (MPa) mean [Range] } \\
\hline & & & & Mean & Median & Mode & Range & \\
\hline \multicolumn{9}{|l|}{ Limestone } \\
\hline 1 & $\mathrm{PO}$ & $\mathrm{n} / \mathrm{a}$ & 21 & 62 & 62 & 64 & $47-76$ & $\begin{array}{l}153 \\
{[76-302]}\end{array}$ \\
\hline 2 & STM & $\mathrm{n} / \mathrm{a}$ & 22 & 54 & 54 & 54 & $32-70$ & $\begin{array}{l}105 \\
{[35-229]}\end{array}$ \\
\hline 3 & SS & $\mathrm{n} / \mathrm{a}$ & 35 & 47 & 47 & 50 & $30-70$ & $\begin{array}{l}76 \\
{[32-229]}\end{array}$ \\
\hline \multicolumn{9}{|l|}{ Mudstone } \\
\hline 1 & $\mathrm{PO}$ & II & 12 & 33 & 32 & 30 & $19-52$ & $\begin{array}{l}36 \\
{[18-83]}\end{array}$ \\
\hline 1 & $\mathrm{PO}$ & --I & 1 & 36 & _- & - & _- & 41 \\
\hline 2 & STM & II & 4 & 19 & 19 & - & $14-23$ & $\begin{array}{l}18 \\
{[15-23]}\end{array}$ \\
\hline 2 & STM & $--\mathrm{I}$ & 6 & 26 & 26 & - & $17-38$ & $\begin{array}{l}25 \\
{[17-45]}\end{array}$ \\
\hline 3 & SS & II & 3 & 14 & 14 & - & $12-15$ & $\begin{array}{l}<10 \\
{[<10-15]}\end{array}$ \\
\hline 3 & SS & $--\mathrm{I}$ & 13 & 27 & 27 & 29 & $14-38$ & $\begin{array}{l}26 \\
{[<10-56]}\end{array}$ \\
\hline
\end{tabular}

where: II and -I denote parallel and perpendicular (orientation), respectively

always runs parallel to the cliff face inferring control of cliff orientation. It should be noted that orientations are affected by local folding and faulting and not necessarily representative of regional structure.

Faulting is characterised by field observations, desk study and geological mapping of aerial photographs from Bing Maps (2019), summarised in Fig. 5. Generally, faults are highly persistent, often $>100 \mathrm{~m}$, with relatively narrow fault zones $(<4 \mathrm{~m})$. Gentle folding exists though the rock mass tends to be less folded where there is a higher limestone proportion. Bedding is sub-horizontal across all localities e.g. at Locality 3 , the beds are northerly dipping at around $10^{\circ}$ varying locally subject folding and faulting.

\section{Rock mass classification and characterisation}

A summary of the rock mass classification results is show in Table 3. For all the classification systems (GSI, RMR, Q) and RQD (\%) system, the joint characteristics are based on the scanline surveys.

It should be stated that GSI (Flysch) is the most applicable classification system for the BLI. Usually, the lowest rock RMR-value is considered for slope stability i.e. by applying the 'weakest' parameters. However, for TBM 'worst-case' PR is when RMR-values are high, accommodated for in this research work by providing a range of input parameters (and results). Q-system's given ranges account for both rock mass variability and uncertainty in parameters. For example, Jw could range from 0.66 to 1 . Discontinuities are mostly dry but with potential to flow. SRF could be 1-2.5 for medium and low stress, respectively. Typical RQD values are $>90 \%$, decreasing within the more mudstone/shale prevalent areas and in proximity to faults.

\section{Lithological logs}

Based on field work observations, Fig. 6 shows the anticipated limestone percentage to the face of $7.0 \mathrm{~m}$ diameter TBM, compared to literature values. Figure 6a shows that the PO member comprises approximately equal proportions of limestone to mudstone and the STM member is similar and a variation in percentage according to stratigraphic position (Fig. 6b). Peaks at the base of the Bucklandi Zone (33\%) and within the Angulata zone (46\%) are attributed to prominent limestone beds. Figure $6 \mathrm{c}$ exemplifies the influence TBM diameter, TBMs of smaller diameter are much more sensitive to changes. The thickness of beds between localities also varied. The PO and STM members have similar bed thicknesses whilst the SS member has much thicker beds (Fig. 6d and e).

This assessment is used as a tool for tunnelling through the BLI, depending on the expected relevant stratigraphy, which can be identified by the ammonite zonation. The percentage of limestone in the face can indicate the potential for reduced PR and/or AR, increased wear to cutting tools and the potential for blockages within the screw conveyor caused by blocks of limestone. In addition to governing the rock mass behaviour and 

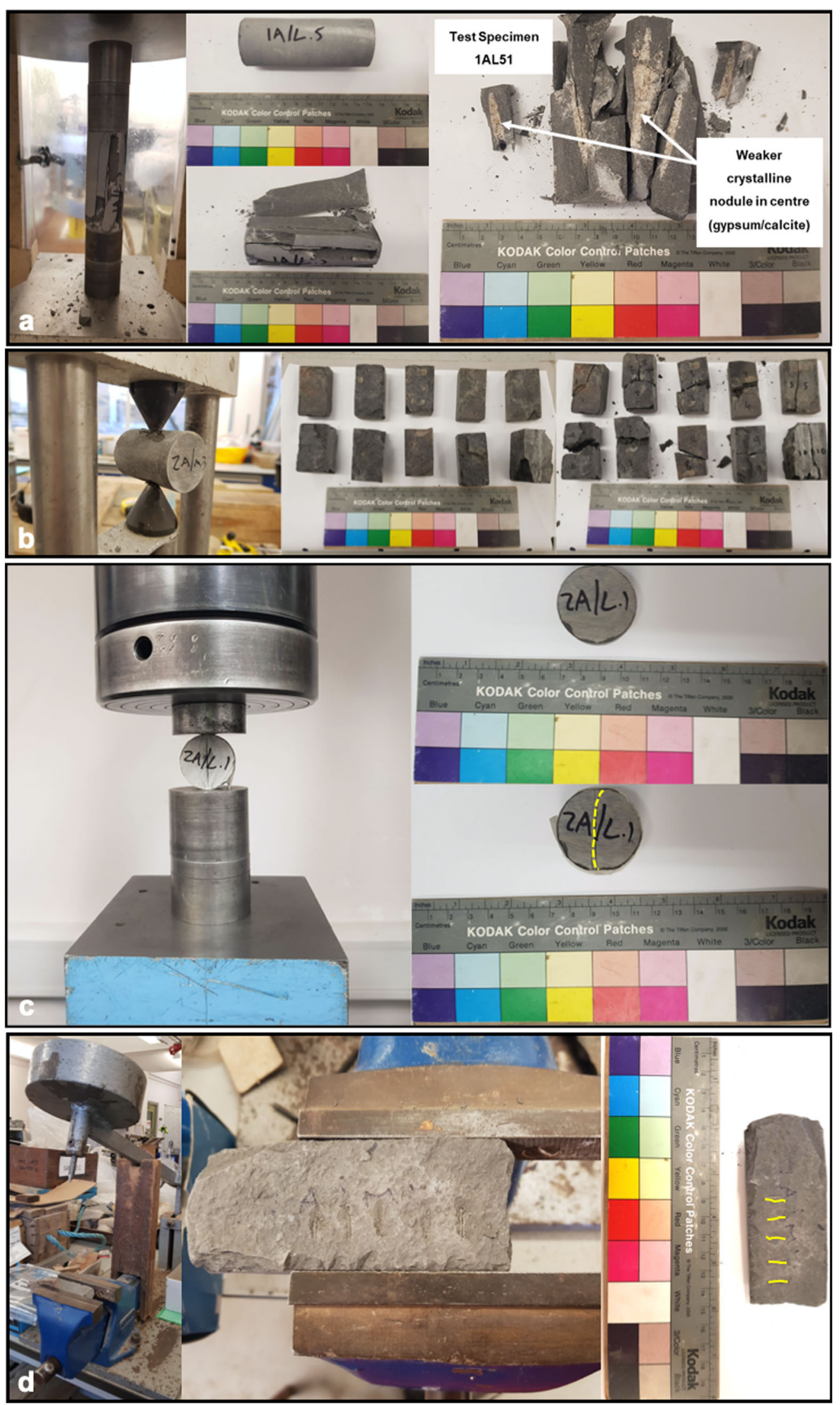

Fig. 7 (a) UCS test; (b) Point Load test; (c) Brazilian test; and, (d) CERCHAR test configuration and post and pre-tested sample mudstone examples for each test 


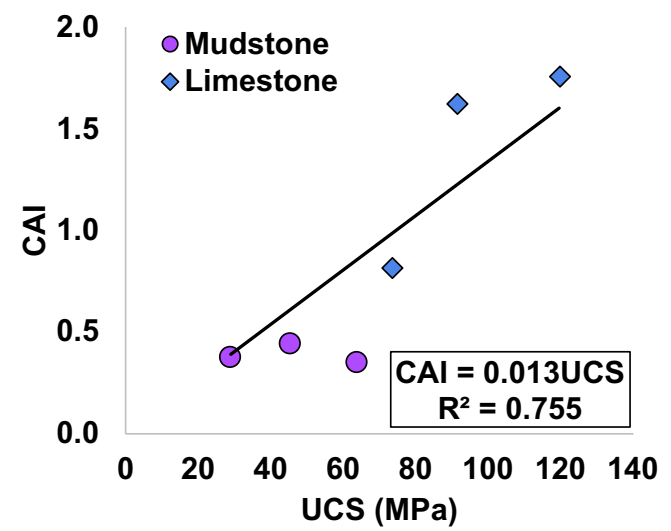

Fig. 8 Relations CAI vs UCS

deformability, as postulated by Glen et al. (2005), stated that for simplicity, the calculation was based upon a 'square' geometry.

\section{Schmidt Hammer}

The L-Type Schmidt Hammer (SH) was selected, following the ISRM guidelines (Aydin 2009). Readings were taken on both limestone and mudstone (the more massive units) on dry, natural exposures. The orientation of the SH axis varied. For the limestone lithologies were achieved 20 readings whereas fewer readings for the mudstone/shale as was too weak with undulating surfaces. According to Aydin (2009), no readings were discarded to ensure that the heterogeneity and range of mechanical properties were encapsulated. The Deere and Miller (1966) method was selected to convert $\mathrm{R}$ values to UCS:

$U C S=6.9 \times 10^{(0.0087 \gamma R+0.16)}$

where: $R$ is the rebound number normalised to vertical and $\gamma$ density $\left(\mathrm{g} / \mathrm{cm}^{3}\right)$.
It should be stated that the use Eq. 3 is considered essential given the high rebound values greater than 60 were often recorded for the limestone, particularly at Locality 1 , exceeding the upper bound of Deere and Miller (1966). Equation 3 was selected given its high regression coefficient and wide applications. For limestone and mudstone, the following unit weights $23 \mathrm{kN} / \mathrm{m}^{3}$ and $22 \mathrm{kN} / \mathrm{m}^{3}$ were used respectively as determined by a simple submersion test. A summary of 117 measurements and conversion to UCS is given in Table 4.

It is critical to note that many of the limestone $\mathrm{SH}$ readings are relatively high. This can occur due to exposure to wetting and drying cycles, that causes solution and re-precipitation of calcium carbonate (Flint et al. 1953), which is plausible given the dynamic tidal regime within the $\mathrm{BCB}$.

\section{Laboratory testing}

To determine the geotechnical properties, laboratory tests were performed on collected samples. Moisture Content (MC), Point Load (PL), Uniaxial Compressive Strength (UCS), Brazilian Tensile Strength (BTS) and CERCHARAbrasivity Tests were completed to provide the required parameters for the discussed performance models. Sample preparation was completed by Soils Engineering Geoservices Ltd. All laboratory testing was conducted at the University of Leeds RMEGG Laboratories, in accordance with the ISRM Suggested Methods (Ulusay and Hudson 2007) unless stated otherwise.

\section{Moisture content}

Eight Moisture Content (MC) tests were completed, using PLtested specimens. Table summarises the MC test results (Table 12). These values are extremely low, attributed the fact that field samples were not sealed, from exposed outcrops. The mudstone samples have a slightly higher MC than

Table 5 Summary of laboratory test results

\begin{tabular}{|c|c|c|c|c|c|c|c|c|c|c|c|}
\hline \multirow[t]{2}{*}{ Member } & \multirow[t]{2}{*}{ Lithology } & \multicolumn{5}{|c|}{ Test(s) performed } & \multicolumn{2}{|l|}{ Compressive strength } & \multirow{2}{*}{$\begin{array}{l}\text { Tensile strength } \\
\text { BTS (MPa) range }\end{array}$} & \multicolumn{2}{|c|}{ Abrasivity } \\
\hline & & $\mathrm{SH}$ & UCS & PL & BTS & CAI & UCS $(\mathrm{MPa})$ range excl. $\mathrm{SH}$ & Category & & CAI & Category \\
\hline PO & Lmst & $\checkmark$ & $\checkmark$ & $\checkmark$ & $\checkmark$ & $\checkmark$ & $73-169$ & Strong to Very Strong & $11.5-14.6$ & 1.8 & Low \\
\hline LVN & Lmst & - & - & - & - & - & - & - & - & - & - \\
\hline STM & Lmst & $\checkmark$ & $\checkmark$ & $\checkmark$ & $\checkmark$ & $\checkmark$ & $80-104$ & Strong to Very Strong & $10.1-13.4$ & 1.6 & Low \\
\hline SS & Lmst & $\checkmark$ & $\checkmark$ & $\checkmark$ & $\checkmark$ & $\checkmark$ & $39-101$ & Medium to Very Strong & $9.2-10.9$ & 0.8 & Very Low \\
\hline PO & Mdst & $\checkmark$ & $\checkmark$ & $\checkmark$ & $\checkmark$ & $\checkmark$ & $7-83$ & Weak to Strong & $6.6-7.2$ & 0.3 & Extremely Low \\
\hline LVN & Mdst & - & - & - & - & - & - & - & - & - & - \\
\hline STM & Mdst & $\checkmark$ & - & $\checkmark$ & $\checkmark$ & $\checkmark$ & $4-88$ & Very Weak to Strong & 3.5 & 0.4 & Extremely Low \\
\hline SS & Mdst & $\checkmark$ & - & $\checkmark$ & - & $\checkmark$ & 45 & Medium Strong & - & 0.4 & Extremely Low \\
\hline
\end{tabular}


limestone, possibly due to their permeability allowing better water retention. In situ MC-values may be closer to $\sim 13.2 \%$ as stated by Hobbs et al. (2012), for the BLI.

\section{Uniaxial compressive strength (UCS) test}

UCS testing was performed primarily on eight limestone samples and a massive mudstone sample (Table 13). The loading rates applied were calculated based on strength estimates to achieve a failure time compliant with the standard: Limestone (S. Wales) $11-15 \mathrm{kN} / \mathrm{min}$; Limestone (Somerset) $8 \mathrm{kN} / \mathrm{min}$ and Mudstone (S. Wales) $2.5 \mathrm{kN} / \mathrm{min}$. It should be stated that samples were $37 \mathrm{~mm}$ in diameter, rather than preferable $54 \mathrm{~mm}$ due to core drilling limitations.

The SS member limestone specimen was very argillaceous, which explains the low UCS. The PO and STM member results were similar. It must be also noted that for two PO member specimens, a strength of $88 \mathrm{MPa}$ was recorded. However, for one specimen, the ends were not squared and loading occurred at a slight angle, likely resulting in lower maximum stress. For the second sample, a crystalline nodule (Fig. 7a) was present in the centre but was not apparent from the exterior of the core. The crack likely propagated from the centre attributing the lower strength to the weaker nature of this infilling, which was very crumbly upon failure. Discounting these two readings would give a much higher mean strength of the PO member of $139 \mathrm{MPa}$.

\section{Point load test}

The PL test is an index test which can be used to predict the UCS, by applying a conversion factor to the PL strength Index $\left(\operatorname{Is}_{(50)}\right)$. Rock specimens, comprising of cores and saw cut blocks, were broken by applying a load through two conical platens. Specimens of both lithologies were tested, but this technique is particularly important for application to the mudstone/shale samples, given these are unsuitable for UCS testing and PL testing is recommended for shales (e.g. Vallejo et al. (1989)). The mudstone/shales are anisotropic; therefore, it was ensured that loading was applied both parallel (II) and perpendicular (-I) to the laminations. This was done so that the strength anisotropy index $\left(\mathrm{I}_{\mathrm{A}(50)}\right)$ could also be determined. Due to invalid failures, 8 of the mudstone tests were discarded; all attributed to lamination effects. It should be noted that due to the limited sample number, specimens from each locality were classed as one sample set, despite likely variations where block samples are taken from different beds. The $\mathrm{I}_{\mathrm{s}(50)}$ results were then converted to UCS (MPa) using:

$U C S=22 I_{s(50)}$

after Brook (1985), as this correlation is supported by the ISRM (2007) and applicable to a variety of rock types. Figure $7 \mathrm{~b}$ shows an example of PL-tested mudstone from the STM member.

The results (Table 14) are also dependent on the choice of conversion correlation. Low water contents may have resulted in higher than in situ UCS values, a correlation found by numerous authors e.g. Romana and Vasarhelyi (2007); who also found this to be more significant for mudstone than limestones, with ratios of $\mathrm{UCS}_{\mathrm{sat}} / \mathrm{UCS}_{\text {dry }}$ of 0.3 and $0.8-9$, respectively. 'Stepped' fractures were observed both in the laboratory and field; attributed to the rock preferentially splitting along laminations. As expected, the strength parallel to laminations was found to be weaker than perpendicular, with $\mathrm{I}_{\mathrm{A}(50)}$ values of 1.92 and 1.58. Regionally, the bedding is mostly sub-horizontal, so typically the force exerted by the cutters would be parallel to the laminations.

\section{Brazilian tensile test}

A total of 20 BTS tests were completed on both lithologies on $37 \mathrm{~mm}$ diameter samples (Table 15, Fig. 7c). The loading rates applied were $300 \mathrm{~N} / \mathrm{s}$ and $200 \mathrm{~N} / \mathrm{s}$ for limestone and mudstone, respectively. For the limestone, the results are consistent and show a similar strength trend of reducing strength from PO, STM to SS member to the UCS testing. Relevant
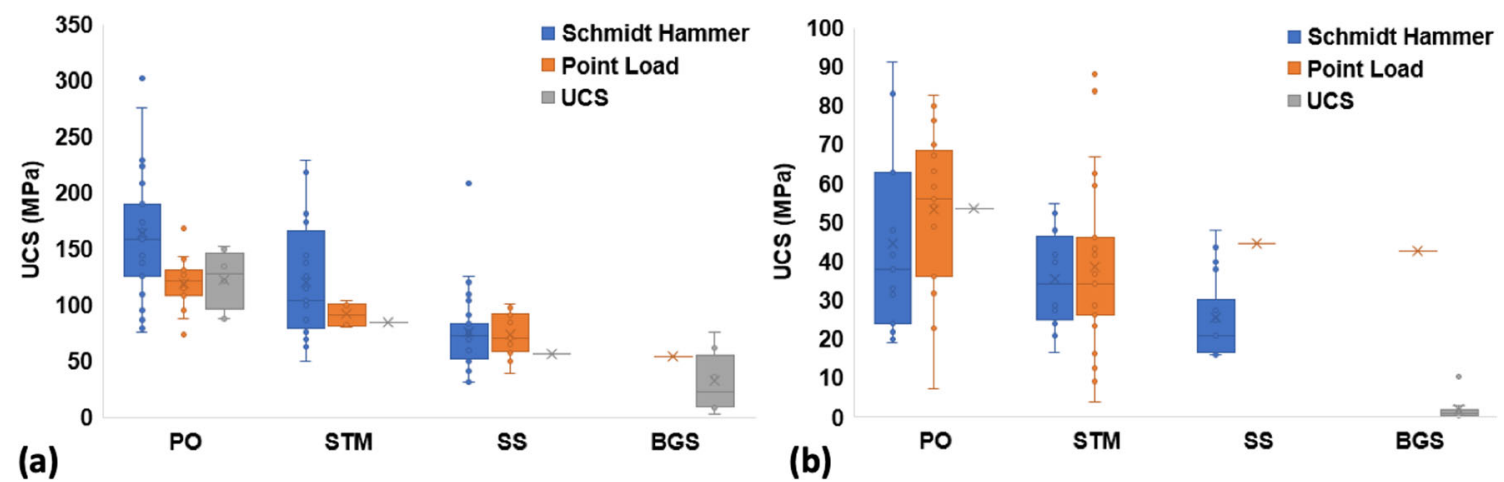

Fig. 9 UCS comparison (a) limestone; (b) mudstone/shale 


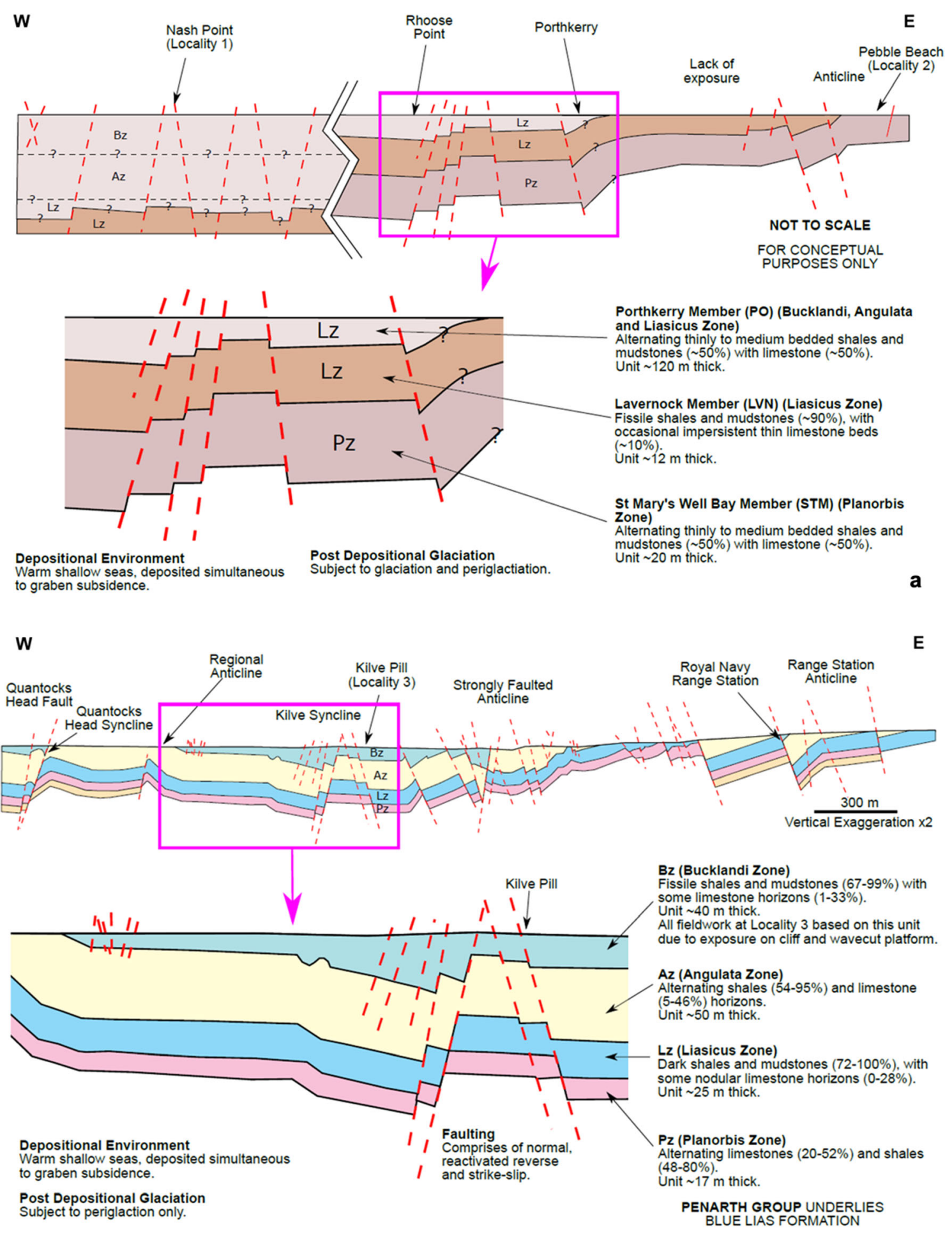

b

Fig. 10 Proposed geological model along (a) S. Wales Coast Structure inferred from Digimaps.; and (b) Somerset Coast

to the mudstone specimens given that for PO member, the strength parallel to laminations was higher than perpendicular. The anisotropy index (AI) defined for the STM member was in line with what was expected (1.7).

\section{CERCHAR Abrasivity Test}

The CERCHAR Abrasivity Index (CAI) Test involves a stylus scratching a rock specimen for $10 \mathrm{~mm}$, to measure the tip wear (Fig. 7d). This test was selected to measure rock 
abrasivity, due to its worldwide usage and acceptance for estimation of cutter consumption (Rostami et al. 2014; Bilgin et al. 2014). CAI is an input parameter for some performance prediction models and provides an estimate of the rate of cutter replacement. The tests were completed in accordance with the ISRM (Alber et al. 2014) to 6 samples and reporting details applicable for all tests (Table 16). The test was conducted under the following conditions: air-dryed environment, rockwell hardness HRC of stylus: 58, measurement method: side view, type of apparatus: type 1 . Tests were completed on the fresh surface of post-PL tested specimens. With the exception of one test specimen, where saw-cut surfaces were used, this was then corrected for according to give CAI'. The side view method was used since Rostami et al. (2014) found this reduces the operator effect on the test, compared with the top view method. Four measurements were taken of each pin and a mean taken (excluding erroneous results) following the example in Alber et al. (2014).

The abrasivity of all the specimens is 'low' to 'extremely low', comparable with typical values for limestone $1-3$, mudstone 1-2 and shale 0.5-1.5 (Bilgin et al. 2014). Rostami et al. (2014) suggests the CAI test may not be suitable for very soft

Table 6 Ground type definition and descriptions

\begin{tabular}{llll}
\hline $\begin{array}{l}\text { Ground } \\
\text { Type }\end{array}$ & Description & GSI & Appearance Example \\
\hline GT1 & $\begin{array}{l}\text { Undisturbed to moderately } \\
\text { disturbed, gently folded rock } \\
\text { mass, with medium thickness } \\
\text { limestone beds }(90 \%) \text { with } \\
\text { occasional thin siltstone/shale } \\
\text { layers }(10 \%) .\end{array}$ & $\begin{array}{l}\text { n/a - hypothetical end } \\
\text { member }\end{array}$ \\
\hline
\end{tabular}

Undisturbed to moderately
disturbed, occasionally gently
folded, rock mass with
alternating thinly bedded
limestones $(50 \%)$ and shales
$(50 \%)$.


Fig. 11 Geological stratigraphy and corresponding GTs

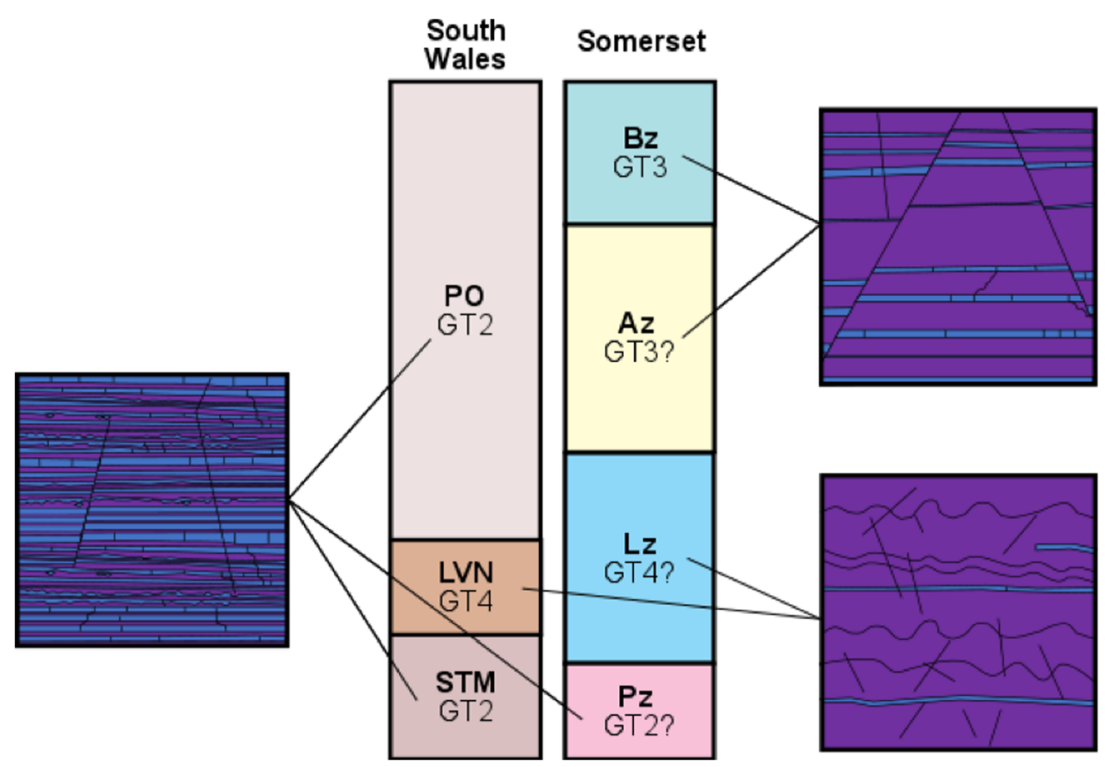

rock where there is little to no wear on the stylus; such as the mudstone/shales in this study. Additionally, during tests the tip penetrated the mudstone. The applied correction factor for sawn surfaces is considered to overestimate the CAI for the mudstone. The quartz content between the lithologies is expected to be broadly similar. The higher CAI for limestone is shown to correlate with rock strength (Fig. 8), (Rostami et al. 2014).

\section{Test result discussion}

Table 5 summarises the various test lab results performed in both lithologies. The UCS values in Fig. 9 show that the intact rock strength of the S. Wales samples (PO and STM member) is notably higher than observed in Somerset (SS member). BGS data for the BLI, from Hobbs et al. (2012), show much lower UCS values, particularly from direct tests. However, their data set is also limited and there is no indication of sampling locations, making comparisons problematic. In the field, mudstone/ shale was observed to be very weak to weak, indicative of UCS-values of 1-25 MPa, compared with 4-83 MPa, from laboratory tests. The strength variation is likely related to the carbonate content, as inferred by Hobbs et al. (2012) who observed strengths of $<5 \mathrm{MPa}$ for samples without carbonate.

\section{Geological and geotechnical model}

Based on the field observations and testing (in situ and lab), first a geological model is developed through the desk study which is further developed to a geotechnical model in order to define rock mass behaviour types, partly following the method of Marinos et al. (2019), Skolidis et al. (2020) and Paraskevopoulou et al. (in press).

\section{Geological model}

The conceptual geological models for both $\mathrm{S}$. Wales and the Somerset coast have been developed and are shown in Fig. 10. Although detailed hydrogeology is unknown, it is rational that a higher percentage of limestone beds, which permit groundwater flow, will correlate with a higher K-value (Royal Haskoning 2009). Weathering is expected to differ either side of the BCB, primarily due to different glaciation histories. Faulting is fairly common and persistent at all localities in particularly at Locality 3, supported by Glen et al. (2005), geological mapping and aerial photography show faulting becoming less common. This suggests a variation in occurrence can be expected, accounting for unforeseen tunnelling conditions.

\section{Geotechnical model}

The geological units have been defined and categorised into ground types (GTs), shown in Table 6 which are expected to behave similarly when excavated.

The Geotechnical Types (GT) units are defined based on GSI, given the importance of discontinuities. The limestone and mudstone are observed to behave in brittle and ductile manners respectively e.g. spalling of limestone during UCS testing and crushing of mudstone during PL tests. Discontinuities also behave differently, vertical discontinuities exist within limestone, which are then 'stepped' through mudstone, taking the line of least resistance. GT1 is a hypothetical end member, included for completeness, comprised mostly of limestone. However, it must be emphasised that this 
Table 7 Geotechnical design parameters based of GTs

\begin{tabular}{llll}
\hline Ground Type & Type 1 (GT1) & Type 2 (GT2) \\
\hline $\begin{array}{l}\text { Schematic } \\
\text { Representation } \\
\text { (see Table 16 for } \\
\text { descriptions) }\end{array}$
\end{tabular}

Key Parameters with ranges given in [ ]

(values in red have been estimated based on engineering judgement)

\begin{tabular}{|c|c|c|c|c|}
\hline $\begin{array}{l}\text { UCS }_{\text {intact }}[\mathrm{MPa}] \\
\text { (Lmst) }\end{array}$ & $\begin{array}{c}106 \\
{[80-152]}\end{array}$ & $\begin{array}{c}106 \\
{[80-152]}\end{array}$ & $\begin{array}{c}39-101 \\
{[73]}\end{array}$ & $\begin{array}{c}39-101 \\
{[73]}\end{array}$ \\
\hline $\begin{array}{l}\text { UCS }_{\text {intact }}[\mathrm{MPa}] \\
\text { (Mdst) (II) }\end{array}$ & $\begin{array}{c}15 \\
{[1-54]}\end{array}$ & $\begin{array}{c}15 \\
{[1-54]}\end{array}$ & $1-54$ [15] & $\begin{array}{l}1-54 \\
{[10]}\end{array}$ \\
\hline $\begin{array}{l}\text { UCS } \text { intact }[\mathrm{MPa}] \\
\text { Weighted } \\
\text { Average }\end{array}$ & $\begin{array}{c}72-142 \\
{[97]}\end{array}$ & $\begin{array}{c}61 \\
{[41-103]}\end{array}$ & $9-63$ [27] & $\begin{array}{l}5-59 \\
{[16]}\end{array}$ \\
\hline $\begin{array}{l}\text { BTS [MPa] } \\
\text { (Lmst) }\end{array}$ & $\begin{array}{c}12 \\
{[10-15]}\end{array}$ & $\begin{array}{c}12 \\
{[10-15]}\end{array}$ & 10 [9-11] & $\begin{array}{c}10 \\
{[9-11]}\end{array}$ \\
\hline $\begin{array}{l}\text { BTS [MPa] } \\
\text { (Mdst) (II) }\end{array}$ & $\begin{array}{c}5 \\
{[4-7]}\end{array}$ & $\begin{array}{c}5 \\
{[4-7]}\end{array}$ & 5 [1-7] & $\begin{array}{c}1 \\
{[1-7]}\end{array}$ \\
\hline $\begin{array}{l}\text { BTS [MPa] } \\
\text { Weighted } \\
\text { Average }\end{array}$ & $\begin{array}{c}11 \\
{[9-14]}\end{array}$ & $\begin{array}{c}9 \\
{[7-11]}\end{array}$ & 6 [3-8] & $\begin{array}{c}2 \\
{[0.5-8]}\end{array}$ \\
\hline $\begin{array}{l}\text { CAI [-] Weighted } \\
\text { Average }\end{array}$ & $\begin{array}{c}1.6 \\
{[0.3-1.8]}\end{array}$ & $\begin{array}{c}1.0 \\
{[0.3-1.8]}\end{array}$ & $\begin{array}{c}0.6 \\
{[0.3-1.8]}\end{array}$ & $\begin{array}{c}0.5 \\
{[0.3-1.8]}\end{array}$ \\
\hline RQD (\%) & $\begin{array}{c}95 \\
{[90-100]}\end{array}$ & $\begin{array}{c}90 \\
{[80-100]}\end{array}$ & $\begin{array}{c}82.5 \\
{[68-97]}\end{array}$ & $\begin{array}{c}25 \\
{[0-50]}\end{array}$ \\
\hline GSI [-] & $\begin{array}{c}60 \\
{[55-65]}\end{array}$ & $\begin{array}{c}48 \\
{[45-50]}\end{array}$ & $\begin{array}{c}42 \\
{[35-48]}\end{array}$ & $\begin{array}{c}33 \\
{[25-40]}\end{array}$ \\
\hline Q [-] & $\begin{array}{c}4.85 \\
{[3-6.7]}\end{array}$ & $\begin{array}{c}2.4 \\
{[1.8-3]}\end{array}$ & $\begin{array}{c}1.9 \\
{[1.8-2]}\end{array}$ & $\mathrm{n} / \mathrm{a}$ \\
\hline RMR [-] & $\begin{array}{c}61-77 \\
{[75]}\end{array}$ & $\begin{array}{c}48-67 \\
{[55]}\end{array}$ & $\begin{array}{c}34-67 \\
{[54]}\end{array}$ & $\mathrm{n} / \mathrm{a}$ \\
\hline $\begin{array}{l}\text { Discont. Spacing } \\
{[\mathrm{m}]}\end{array}$ & $\begin{array}{c}0.10-4.30 \\
{[0.72]}\end{array}$ & $\begin{array}{c}0.01-4.30 \\
{[0.53]}\end{array}$ & $\begin{array}{c}0.01-1.99 \\
{[0.22]}\end{array}$ & $\mathrm{n} / \mathrm{a}$ \\
\hline JRC [-] & $6-10$ & $0-10$ & $0-10$ & $\mathrm{n} / \mathrm{a}$ \\
\hline $\begin{array}{l}\text { Discont. } \\
\text { Persistence [m] }\end{array}$ & $0.04->100$ & $0.04->100$ & $0.05->100$ & $\mathrm{n} / \mathrm{a}$ \\
\hline
\end{tabular}

Determined Parameters (derived using Rocdata of Rocscience for tunnel depth of $50 \mathrm{~m}$ )

\begin{tabular}{lcccc}
\hline UCS ${ }_{\text {rock mass }}[\mathrm{MPa}]$ & 10 & 3 & 1 & 0.4 \\
\hline Friction Angle [0] & 56 & 28 & 26 & 23 \\
\hline Em [GPa] & 45.4 & 3.9 & 1.2 & 0.4 \\
\hline
\end{tabular}

Rock Mass Behaviour (types from Marinos et al., 2019)

\begin{tabular}{llccc}
\hline $\begin{array}{l}\text { Small } \\
\text { Overburden }\end{array}$ & Wg & Ch-Wg; Sh & Ch-Wg; Sh & Ch-Wg; Sh; Sh-Rv \\
\hline $\begin{array}{l}\text { Large } \\
\text { Overburden }\end{array}$ & St-Wg & Sh;Wg & Sh-Sq; & Sq-Ch; \\
\hline
\end{tabular}

Where: Wg-Wedge failure, Ch-Chimney type failure, Rv-Ravelling ground, Sq-Squeezing ground, St-Satble ground, Sh-Shear failure 
GT1 was not observed in the field. The allocation of GTs to geological units within the BLI is shown in Fig. 11 with question marks denoting units that require visual verification. Justification is given in Appendix A.1.

Table 7 summarises the allocated geotechnical parameters and expected ground behaviour. Where possible, design values (and ranges) are obtained from laboratory results (excluding outliers), e.g. for GT1 (limestone) an average strength of PO and STM members is taken. Where laboratory results are missing or unrepresentative, values are estimated based on field observations, e.g. for the mudstone given the sampling bias.

UCS is a required parameter for many PR prediction models. However, for heterogeneous conditions, there are no suggested guidelines on how to determine a single UCS value. However, the presented research work makes the following recommendation: the design value is determined by a weighted method based on percentage limestone. For example, in the case of $20 \%$ limestone and $80 \%$ mudstone the calculation is:

$$
\begin{aligned}
U C S_{\text {intact }}= & 0.2 \times U C S_{\text {intact }}(\text { lmst })+0.8 \\
& \times U C S_{\text {intact }}(m d s t)
\end{aligned}
$$

The limitations and further recommendations, when applying this to PR prediction, are discussed in the next section. The same system is also used for other parameters e.g. BTS and CAI.

The deformation modulus $\left(\mathrm{E}_{\mathrm{m}}\right)$ derived by RocData (by Rocscience) gives the rock mass stiffness and may also be used as a proxy for structure i.e. higher $\mathrm{E}_{\mathrm{m}}$-values are correlated to higher limestone proportions, resulting in open folds with low amplitudes and minimal disturbance, and vice versa; as observed by Glen et al. (2005). It is important to understand how a cavity within the rock mass will behave without the support from the TBM. Therefore, potential failure mechanisms (Rock Mass Behaviour Type - RMBT) are also identified in Table 8 based on work by Marinos et al. (2019).

\section{Tunnelling considerations and design analysis}

The variation in geomechanical facies has an unknown but potentially large effect on AR. GT1 and GT4 represent the likely endmembers that could occur in the BLI. These are not necessarily 'best' and 'worst' cases, GT1 creates the most resistance to instantaneous PR, whilst GT4 would require the most support. The following analysis determines the difference in TBM performance between these GTs; hence, how sensitive to GT the design should be. Machine specifications are required for most PR models; therefore, hypothetical TBM specifications (Table 8). A 7.0 m EPB machine was selected for applicability in unstable (failure can occur) conditions and adaptability to changing geology.

A quantitative estimate of PR was completed using the models outlined in Table 2 and parameters derived in Table 9. Each GT design parameter (Table 8) is kept constant, enabling comparison between models. Unless otherwise stated, uncertainty bounds are based on parameter ranges. The applied models were chosen based on industry recognition, the applicability to the geological formation and laboratory equipment availability. A sensitivity analysis for each model has been performed to determine which parameters are most influential shown in Figs. 12, 13, 14, 15 and 16.

\section{CSM model by Rotsami}

The CSM model shows an increase in calculated PR, or, required thrust reduction to maintain a constant PR from GT1GT4 (Figure 17a and b); this is partly expected due to decreasing percentages of limestone, limiting PR. However, unrealistically high values are calculated for GT3 and GT4; attributed to actual PR being limited by unconsidered technical issues. In reality, there is an upper PR limit of around $5 \mathrm{~m} / \mathrm{h}$, as suggested by Barton (2000), as the operator would reduce the thrust to accommodate for poor ground conditions.

\section{$\mathbf{Q}_{\text {TBM }}$ model by Barton}

Results from the $\mathrm{Q}_{\text {TBM }}$ model are shown in Fig. 17c and the Q-system was considered inapplicable to GT4 due to its very weak nature. Calculations apply $\sigma_{\mathrm{cm}}$ given that joints are mostly vertical so joint inclination $(\beta)$ is around $90^{\circ}$ and therefore 'unfavourable'. Uncertainties shown account for variations in UCS, Q and quartz content only. Again, the predicted PR exceeds realistic values (Fig. 13). Similar overestimations were experienced by Hassanpour et al. (2016) when using the

Table 8 Hypothetical EPBM specifications

\begin{tabular}{lll}
\hline Parameter & Value & Model(s) \\
\hline Machine diameter (m) & 7 & n/a \\
Speed (rpm) & 3 & All \\
Max cutter force (kN/cutter) & 267 & All \\
Number of disc cutters $(-)$ & 46 & CSM, MCSM \\
Max. operating thrust $(\mathrm{kN})$ & 12,282 & CSM, MCSM \\
Disc nominal spacing $(\mathrm{mm})$ & 90 & CSM, MCSM \\
Power $(\mathrm{kW})$ & 1.5 & CSM, MCSM \\
Torque $(\mathrm{MN} \mathrm{m})$ & 5 & CSM, MCSM \\
\hline
\end{tabular}




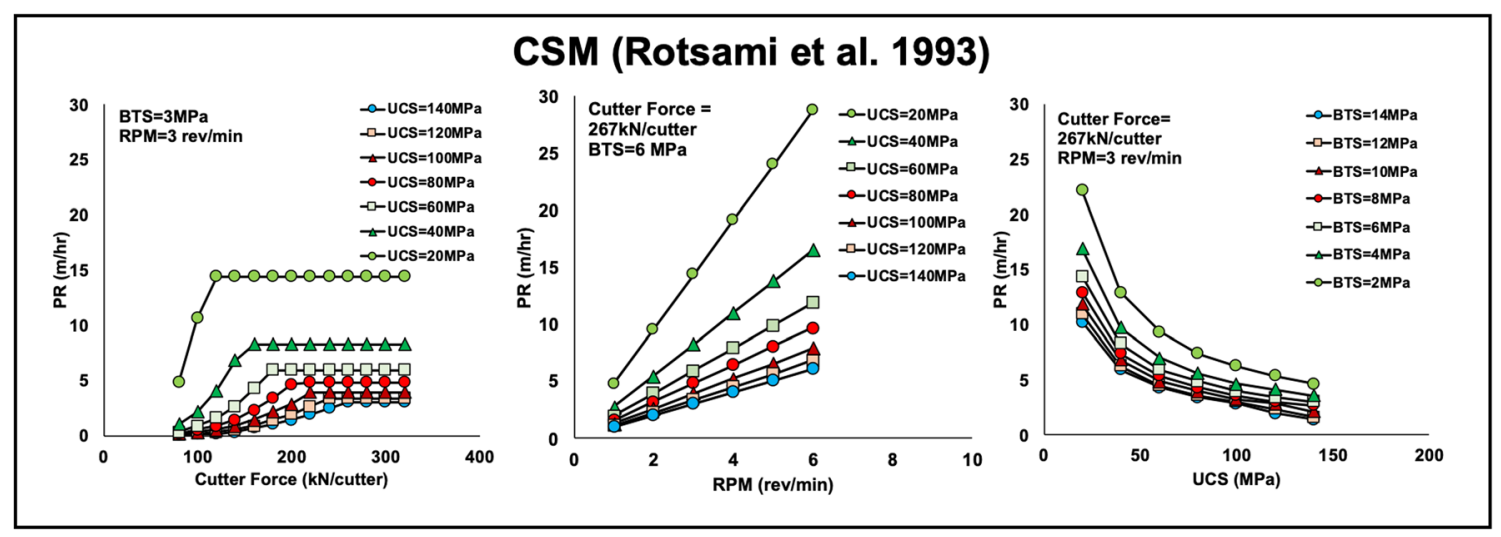

Fig. 12 Sensitivity analysis of the CSM model (Rostami and Ozdemir 1993)

$\mathrm{Q}_{\mathrm{TBM}}$ model, who attributed this to uncertain input parameters e.g. in situ stress. The sensitivity analysis shows cutter thrust is the most influential parameter; along with the Q-value if less than 5. Therefore, the change in predicted PR is largely related to Q-value in this study. The tangential (wall) stress was calculated using the Kirsch equations, assuming a k-value of 0.5 and a depth of $50 \mathrm{~m}$, for which the model is relatively sensitive. Maximum machine cutter thrust was used; this results in $\mathrm{Q}_{\mathrm{TBM}}$ values being lower than 1, which is purely theoretical according to Barton (2000). In this circumstance, thrust is generally reduced particularly where faulting is encountered, to maintain a steady PR as shown in Fig. 17d.

\section{Models by Farrokh and Hassanpour}

The models by Farrokh and Hassanpour give similar results (Fig. 17e), which are all realistic giving PRs below $5 \mathrm{~m} / \mathrm{h}$. The PR increases between GT1-4, associated with the reduced limestone proportion. These models include only RPM and cutter force as machine parameters. The Hassanpour (RMCI) and Farrokh models (Figs. 14 and 15) use only geological parameters derived from laboratory testing; this reduces uncertainty in parameter estimation and provides fewer sources of error. The Hassanpour (GSI) uses the flysch GSI system which is considered accurate for this rock mass. The sensitivity analysis shows these models are most sensitive to UCS,

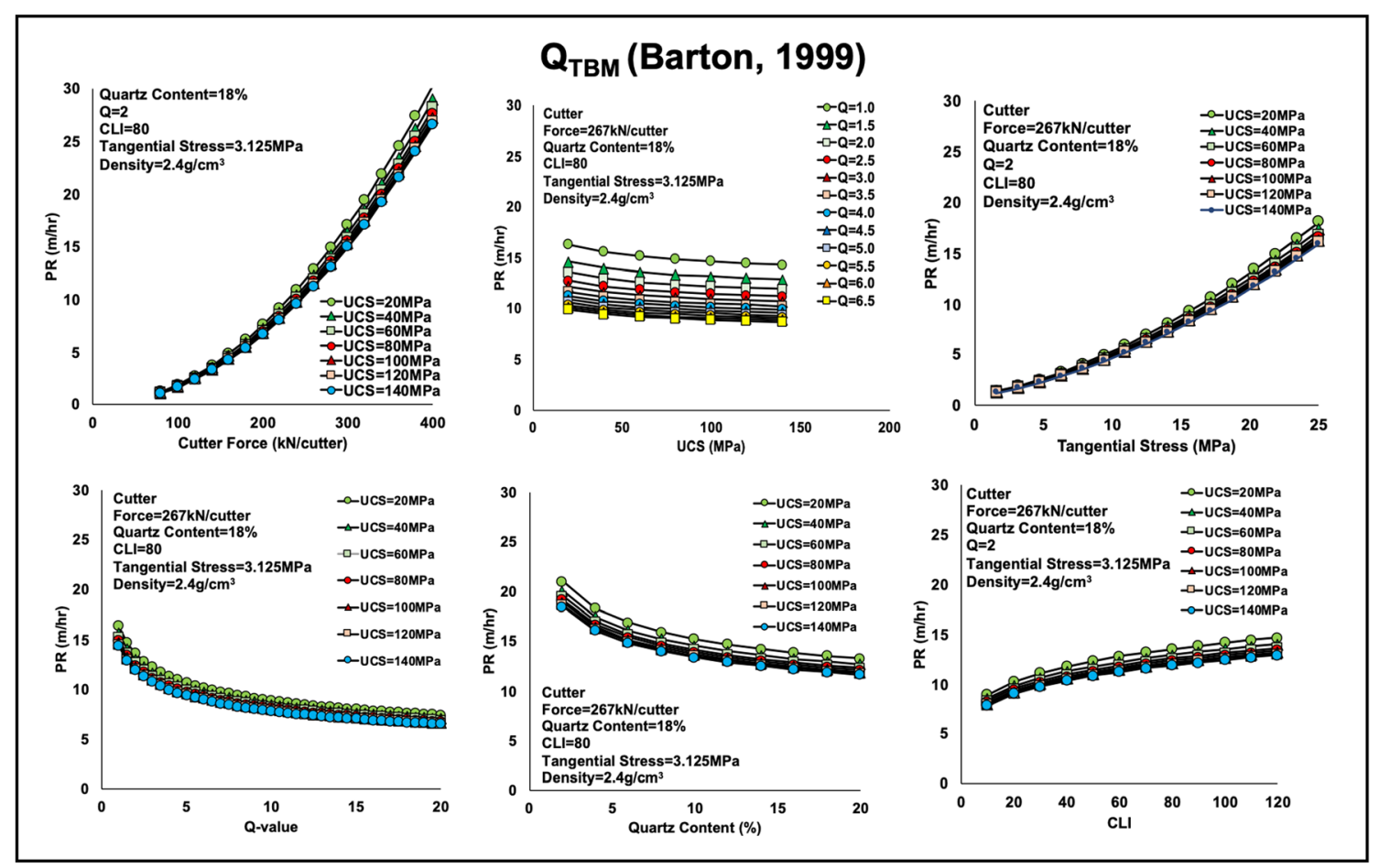

Fig. 13 Sensitivity analysis of the $\mathrm{Q}_{\mathrm{TBM}}$ model (Barton 1999) 


\section{Hassanpour (et al. 2009)}
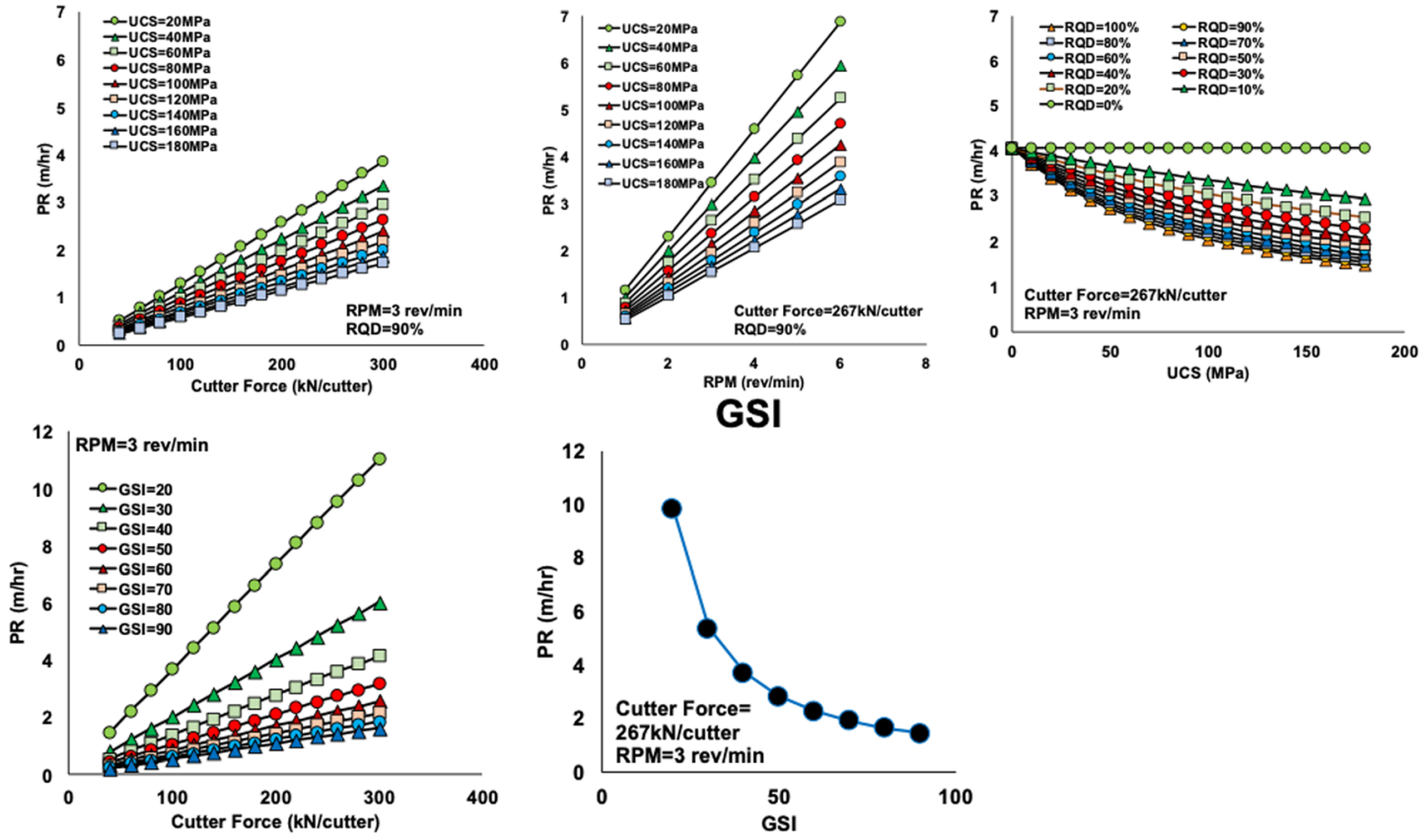

Fig. 14 Sensitivity analysis of the Hassanpour et al. (2009) MRCI and GSI model

RPM and cutter thrust. For the Hassanpour's (RMCI) model, PR is most sensitive to changes in UCS at high RQD values; whilst the Farrokh's model shows the reverse. The high sensitivity to machine parameters demonstrates the importance of keeping these constant when comparing models.

\section{Model by Alber}

The model by Alber (2000) is the only one where the PR decreases between GT1-3 (Fig. 17f), resulting from reduced rock mass strength below $15 \mathrm{MPa}$ and subsequent drop in achievable PR. In this sense, this model is perhaps the most

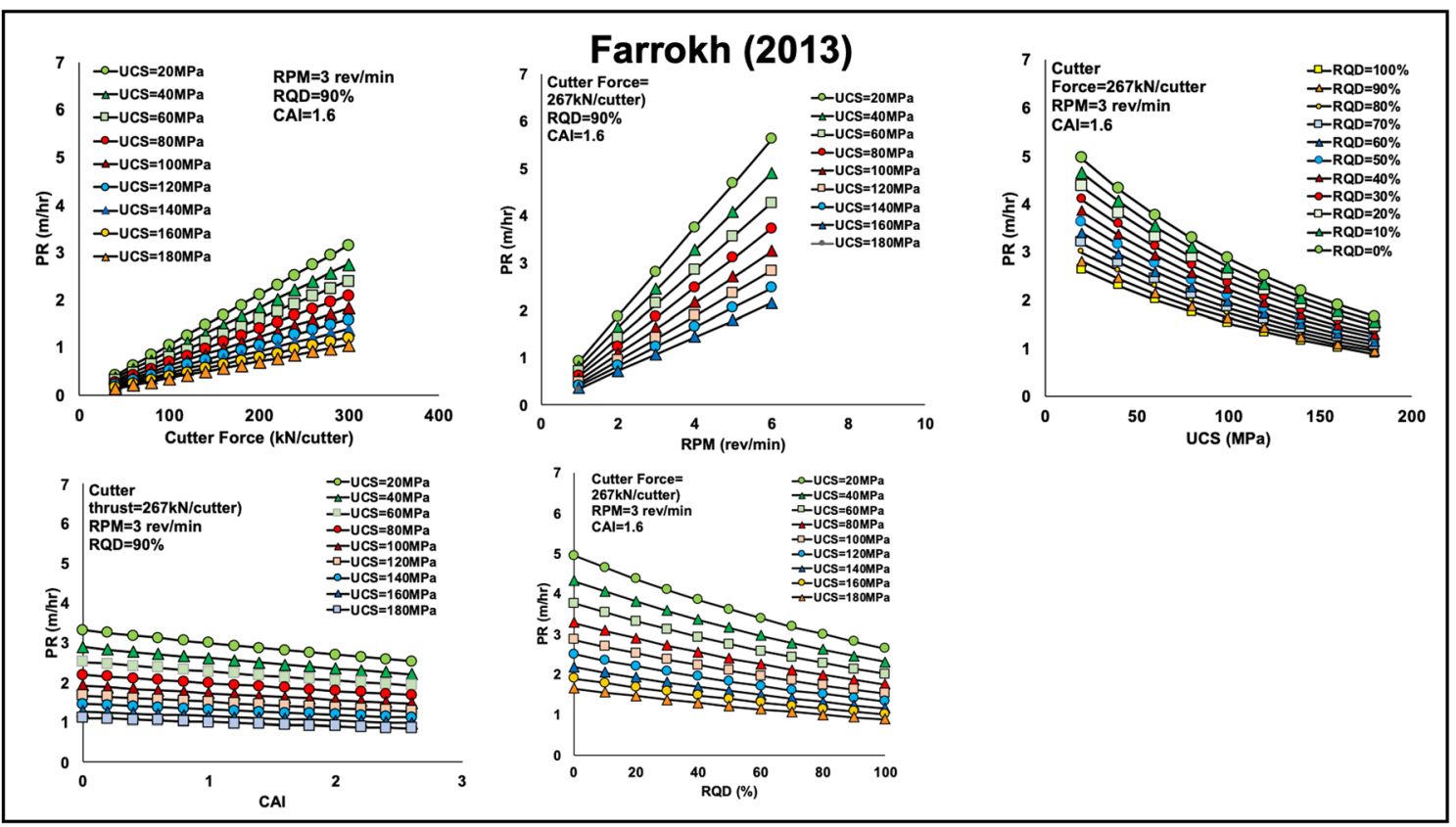

Fig. 15 Sensitivity analysis of the Farrokh (2013) model 


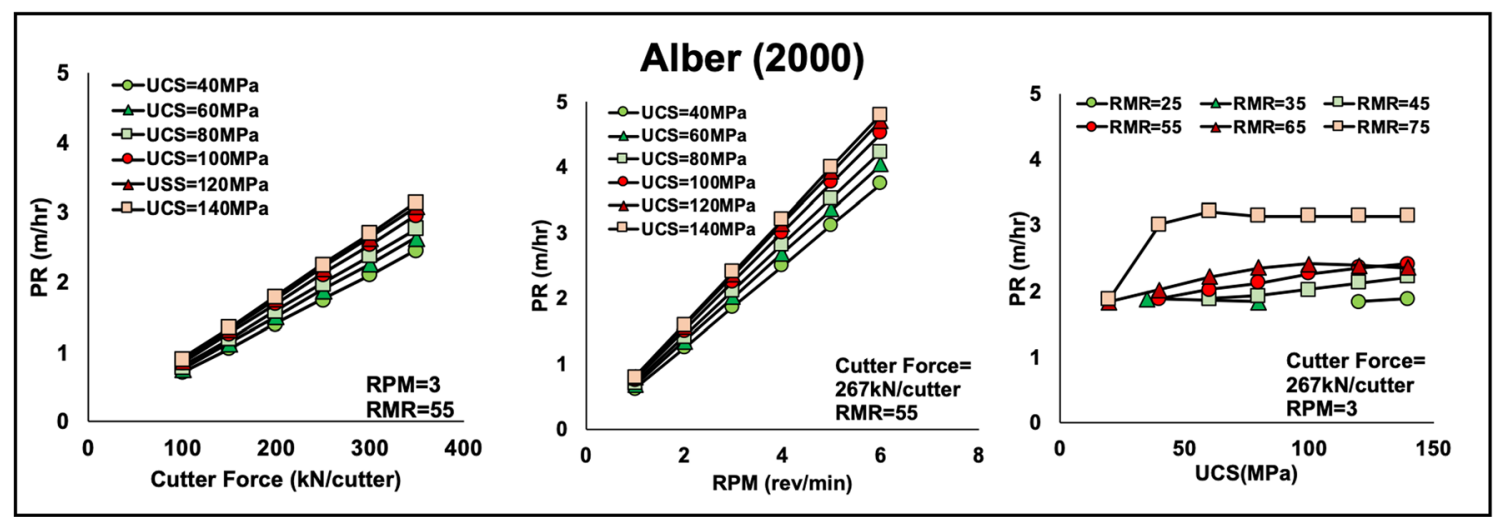

Fig. 16 Sensitivity analysis of the Alber (2000) model

realistic. The model is not applicable to rock masses with RMR-values below 25, i.e. GT4. The sensitivity analysis shows (Fig. 16) this model is mainly sensitive to changes in RPM and cutter thrust, though the trends are unclear due to the model's accountability for reduced thrust.

\section{Model comparison and discussion}

A comparison between the models, given in Figure 18 shows large variation in PR prediction for each GT, highlighting the difficulties and inconsistency in predicting $\mathrm{PR}$. The $\mathrm{Q}_{\mathrm{TBM}}$ model infers that PR is not at all sensitive to the different GTs being limited solely by technical factors. Models by Hassanpour et al. 2009 and Farrokh (2013) best show the anticipated results, where PR is almost doubled between GT1-GT4, attributed to the reduced presence of strong limestone at the face. The model by Hassanpour (RMCI) is assumed to be the most accurate for these ground conditions. It should be noted that constant thrust was used to compare models and GTs; however, in practice, applied thrust varies according to ground conditions (Nelson 1983).

\section{Utilisation and advanced rate}

Utilisation was calculated as a function of stress (tunnel depth) shown in Fig. 19, using Alber (2000). The tangential wall stress was calculated using the Kirsch equations, assuming a k-ratio of 0.5. As expected, GT4 has the lowest U-values, given the weaker rock mass requiring more support. That said, for a $50 \mathrm{~m}$ deep excavation, the U-value does not vary much (between 42.5 and $45 \%$ ), showing that stress has a greater influence in UCS for this model. At higher stresses (e.g. $200 \mathrm{~m}$ ), the effect of UCS variation is notably more pronounced. This can then be applied to Eqs. 1 and 2 to determine the AR, using results from this section.

'Average' ground performance giving an m-value of -0.2 can be assumed, as significant grouting or very bad ground is not anticipated. This is applied to the PR from the Hassanpour (RMCI) model to estimate AR (Table 9).
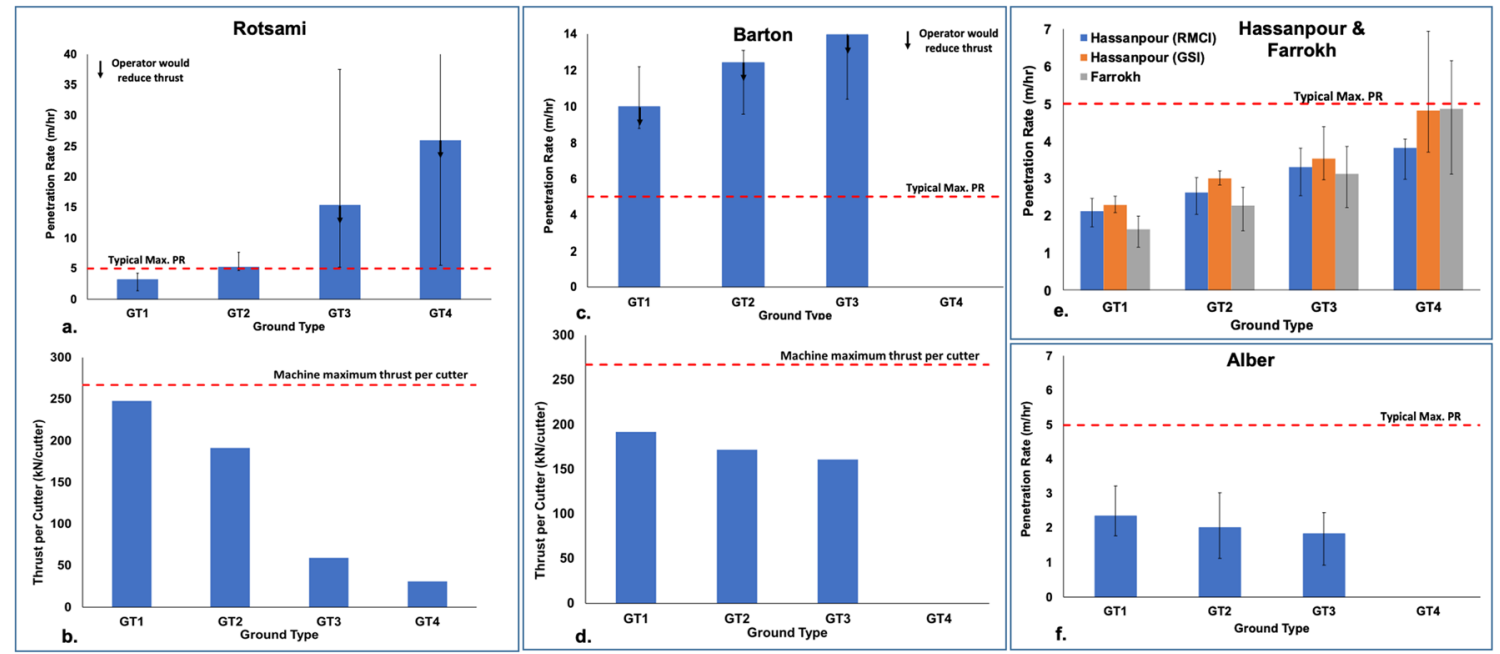

Fig. 17 (a) PR prediction (CSM model); (b) Thrust per cutter with constant PR of $3.24 \mathrm{~m} / \mathrm{h}$; (c) PR prediction ( $\mathrm{Q}_{\mathrm{TBM}}$ model); (d) Thrust cutter with constant PR of $5 \mathrm{~m} / \mathrm{h}$; (e) PR prediction using the Farrokh

and Hassanpour models; and, (f) Model by Alber. Error bars show the $90 \%$ and $10 \%$ percentiles of the model, based on the characteristic input parameters 
Fig. 18 PR prediction model comparison, where PR is capped at $5 \mathrm{~m} / \mathrm{h}$

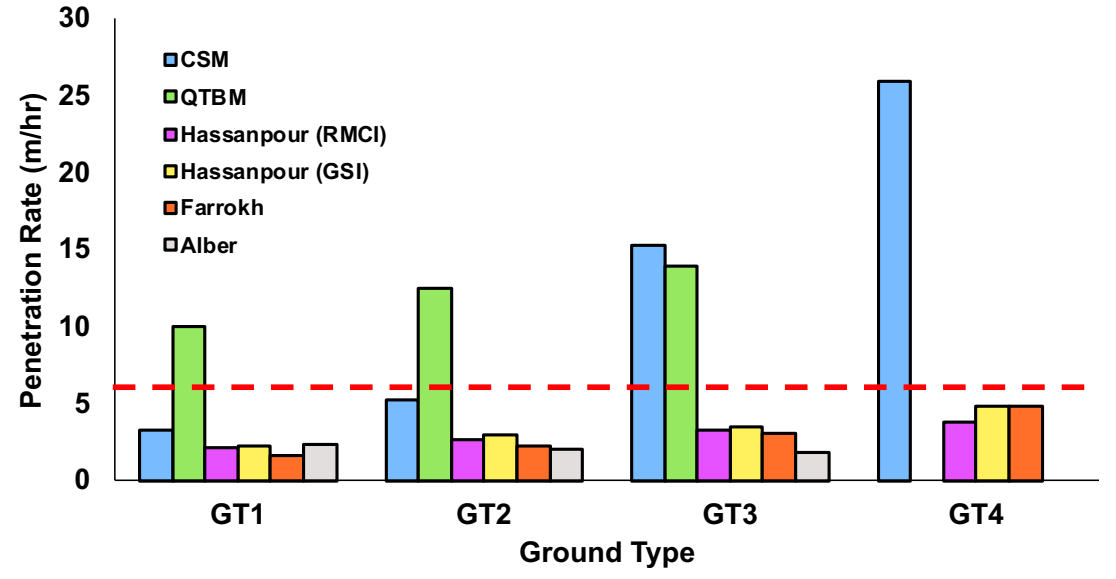

\section{Concluding remarks}

The principal aim of this research work is to propose a methodology, a modified approach, to preliminary assess TBM performance in heterogeneous rock masses based on primary collection data derived from field, in situ and lab testing using the existing empirical models. For this purpose, a desk study assessed the BLI formation in a lithological system consisting of mudstone and limestone layers. Based on the detailed fieldwork, the geological models for both the S. Wales and Somerset were developed. The BLI comprises varying proportions and thicknesses, of persistent, interbedded limestones and calcareous shale and mudstones. Intact rock strength, tensile strength and abrasivity were characterised by laboratory testing on collected samples confirming the expected strength difference between the mudstone/shales and limestone. Additionally, samples from S. Wales were found to be broadly stronger compared with those from Somerset. Abrasivity is determined to be negligible. From the above, a geotechnical model was developed based on which four ground types were determined, distinguished primarily by GSI and limestone percentage. Design values were

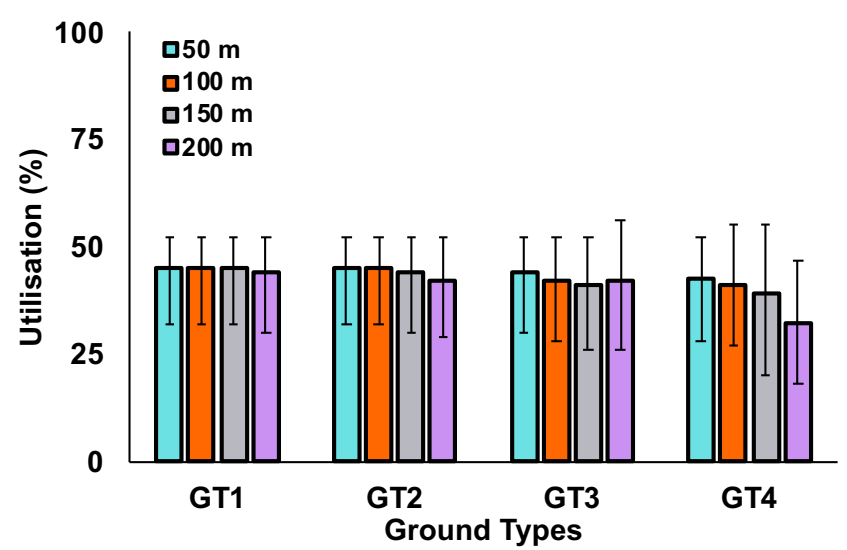

Fig. 19 Utilisation determined by model from Alber. Error bars show the 75 th and 25 th percentiles from model obtained from laboratory results where possible but were otherwise estimated. Implications for TBM performance were assessed. For example, faulting is concluded to be manageable, with most faults unlikely to be recognised by a TBM. Percentage limestone has been identified to be critical for predicting PR, structural disturbance and tunnel convergence. The current PR models do not address the issue of parameter selection for heterogeneous rock masses comprising layers with different rock strengths. Therefore, a weighting system, proportional to the percentage of limestone present in the face, is proposed and applied to the selected PR models for the identified GTs. For the Hassanpour et al. (2009) and Farrokh (2013) models, PR decreases with increased limestone in the face, as expected. Whilst for the CSM and $\mathrm{Q}_{\mathrm{TBM}}$ models, the TBM PR is found to be insensitive to ground type, limited instead by machine restrictions. It was established, from critical review that the Hassanpour et al. (2009) PR prediction models are most applicable to the BLI and consequently to similar heterogeneous lithologies. $U$ is also estimated, employing models by Alber (2000) and Barton (2000), the latter was used to establish preliminary estimates of AR using PR values calculated by the Hassanpour's RMCI model.

Overall, desk study, site reconnaissance, laboratory testing and development of the geological and geotechnical models have all been employed to characterise the rock mass of the BLI and estimate TBM performance. This reduces the risk of cost and time overruns; however, there is always uncertainty in geomaterial distribution (Yau et al. 2019, 2020). The employed methods are crucial, but ground investigation (i.e. boreholes) is still favoured to collecting data from exposures, however it is commonly absent. This work provides guidance on how primary collection dataset can add valuable insights to preliminary assess TBM performance in heterogeneous rock masses. It has been shown how every step of this work starting from field observations to lab testing to developing a 
Table 9 AR estimates using Barton's model (2000)

\begin{tabular}{|c|c|c|c|c|c|c|c|c|}
\hline PR from Hassanpour (RMCI) model & & PR & 1 shift & 1 day & 1 week & 1 month & 3 months & 1 year \\
\hline \multirow[t]{5}{*}{$\operatorname{AR}(\mathrm{m} / \mathrm{h})$} & $\mathrm{U}(\%)$ & 100 & 66 & 53 & 36 & 27 & 22 & 16 \\
\hline & GT1 & 2.12 & 1.4 & 1.12 & 0.76 & 0.57 & 0.46 & 0.34 \\
\hline & GT2 & 2.61 & 1.72 & 1.38 & 0.94 & 0.7 & 0.56 & 0.43 \\
\hline & GT3 & 3.3 & 2.18 & 1.75 & 1.18 & 0.89 & 0.71 & 0.54 \\
\hline & GT4 & 3.81 & 2.52 & 2.02 & 1.37 & 1.02 & 0.82 & 0.62 \\
\hline
\end{tabular}

geological and then geotechnical model can contribute in TBM assessment performance.

Finally, it should be noted that there is a gap in the literature for a more complex method to be developed, which should be verified by laboratory cuttability tests. Additional fieldwork and laboratory testing, incorporating a much larger suite of data, from all the stratigraphic zones within the BLI and comparison of results with borehole data, is recommended, for more detailed characterisation of the BLI. The variability of ground conditions has been simplified by the proposed ground types e.g. properties of PO and STM members are averaged to form GT2. The ground types could be further developed, and visual verification is still required for some geological zones. The weighted average method applied to input parameters for the PR models, is overly simple and it can be used at a preliminary design stage. Further work being considered by the authors includes extending this method to other sites showing natural lithological variations in stratigraphic sequences as well as assessments of how this proposed methodology could be adapted and applied to synthetic rock masses. It is recommended that a larger suite of samples is tested, covering additional localities/stratigraphic zones and comparisons made with borehole data. Testing to further characterise mudstone anisotropy is also suggested.

\section{Appendices}

Table 10 Summary of key activities during fieldwork

\begin{tabular}{|c|c|}
\hline Task and field equipment & Methodology \\
\hline Engineering geological descriptions & Completed in accordance with BS 5930:2015 \\
\hline Standard geological field equipment & Using Guide to Identification and Logging by Soils Engineering \\
\hline Discontinuity surveys & Discontinuities intersecting $30 \mathrm{~m}$ tape measured systematically \\
\hline Tape measures ( $3 \mathrm{~m}$ and $30 \mathrm{~m})$ & 3 orthogonal directions measured (if safe) \\
\hline Scanline sheets from Bell (2000) & 12 surveys completed \\
\hline \multicolumn{2}{|l|}{ Standard geological field equipment } \\
\hline $\begin{array}{l}\text { Observations/measurements of } \\
\text { Macroscale structures }\end{array}$ & Recorded in field notebook. Photographs taken \\
\hline Standard geological field equipment & Coupled with aerial maps to give a broader view \\
\hline Sample collection & $29 \mathrm{lmst}$ and $14 \mathrm{mdst}$ samples collected. Some from recent rockfalls. Specimens not sealed to maintain water content \\
\hline \multicolumn{2}{|l|}{ Hammer and chisel } \\
\hline Rock mass classification & Application of RQD, Q, RMR and GSI (flysch system) \\
\hline \multicolumn{2}{|l|}{ Self-compiled booklet of methods } \\
\hline Bed thickness lithology logs & 5 logs completed \\
\hline $3 \mathrm{~m}$ tape measure & $\begin{array}{l}\text { Measured bed thickness from cliff face/or wave cut platform where cliff unsafe. Corresponding beds matched either } \\
\text { side of faults where possible }\end{array}$ \\
\hline $\begin{array}{l}\text { Schmidt Hammer (SH) measurements } \\
\text { L-type SH }\end{array}$ & Following the updated ISRM (Aydin 2009) \\
\hline
\end{tabular}


Table 11 Scanline survey summary (v=very; ex=extremely)

\begin{tabular}{|c|c|c|c|c|c|c|c|c|c|}
\hline Locality & Set & $\begin{array}{l}\text { Dip/Dip } \\
\text { Direction }\end{array}$ & $\begin{array}{l}\text { True Spacing } \\
(\mathrm{m}) \text { (Mean } \\
{[\text { STDEV]) }}\end{array}$ & Type(s) & $\begin{array}{l}\text { Persistence } \\
(\mathrm{m})\end{array}$ & Aperture & $\begin{array}{l}\text { Nature of } \\
\text { infilling }\end{array}$ & $\begin{array}{l}\text { Surface } \\
\text { Roughness }\end{array}$ & $\begin{array}{l}\text { Water/ } \\
\text { flow }\end{array}$ \\
\hline 1 & 1 & $89 / 351$ & $1.32[1.65]$ & Joint & $0.04-0.68$ & $\begin{array}{l}\text { Tight to } \\
\text { v.narrow }\end{array}$ & $\mathrm{n} / \mathrm{a}$ or clean & Smooth to rough & Dry \\
\hline 1 & 2 & $84 / 258$ & $0.34[0.27]$ & Joint & $>100$ & $\begin{array}{l}\text { Tight to } \\
\text { v.narrow }\end{array}$ & $\mathrm{n} / \mathrm{a}$ or clean & Smooth to rough & Dry \\
\hline 1 & 3 & $4 / 147$ & $0.58[0.32]$ & $\begin{array}{l}\text { Shear/bedding/ } \\
\text { joint }\end{array}$ & $0.5 \rightarrow 5$ & $\begin{array}{l}\text { Tight to } \\
\text { v.narrow }\end{array}$ & $\begin{array}{l}\mathrm{n} / \mathrm{a} \text { or surface } \\
\text { staining }\end{array}$ & Smooth to rough & Dry \\
\hline 2 & 1 & $88 / 054$ & 3.97 & Joint & $>15$ & $\begin{array}{l}\text { Tight to } \\
\text { ex.narrow }\end{array}$ & $\mathrm{n} / \mathrm{a}$ or clean & Smooth to rough & $\begin{array}{l}\text { Dry to } \\
\text { seeping }\end{array}$ \\
\hline 2 & 2 & $88 / 158$ & $0.37[0.34]$ & Joint/fault & $0.4-16$ & $\begin{array}{l}\text { Tight to } \\
\text { v.narrow }\end{array}$ & $\begin{array}{l}\mathrm{n} / \mathrm{a} \text {, clean or } \\
\text { surface staining } \\
\text { or cemented }\end{array}$ & $\begin{array}{l}\text { Smooth to defined } \\
\text { ridges }\end{array}$ & $\begin{array}{l}\text { Dry to } \\
\text { seeping }\end{array}$ \\
\hline $3 a$ & 1 & $81 / 359$ & $0.19[0.18]$ & Joint/fissure & $0.05->7$ & $\begin{array}{l}\text { Tight to } \\
\text { ex.narrow }\end{array}$ & $\begin{array}{l}\text { n/a, clean, surface } \\
\text { staining or } \\
\text { calcite/gypsum }\end{array}$ & $\begin{array}{l}\text { Smooth to rough } \\
\text { (joints); very } \\
\text { rough (fissure) }\end{array}$ & Dry \\
\hline $3 a$ & 2 & $85 / 269$ & $0.23[0.15]$ & Joint & $0.07->3$ & $\begin{array}{l}\text { Tight to } \\
\text { ex.narrow }\end{array}$ & $\begin{array}{l}\mathrm{n} / \mathrm{a} \text {, surface staining } \\
\text { or calcite/gypsum }\end{array}$ & Smooth to rough & Dry \\
\hline $3 a$ & 3 & $4 / 133$ & $0.29[0.37]$ & Joint/bedding & $\begin{array}{l}0.05-0.43 \text { (joints); > } 100 \\
\quad \text { (bedding) }\end{array}$ & Tight & $\mathrm{n} / \mathrm{a}$ & Smooth & Dry \\
\hline $3 b$ & 1 & $74 / 161$ & $0.44[0.48]$ & Joint & $0.07->15$ & $\begin{array}{l}\text { Tight to } \\
\text { v.narrow }\end{array}$ & $\begin{array}{l}\mathrm{n} / \mathrm{a} \text {, surface staining } \\
\text { or calcite/gypsum }\end{array}$ & Smooth to rough & Dry \\
\hline $3 b$ & 2 & $90 / 252$ & $0.64[0.45]$ & Joint/fault & $\begin{array}{l}0.09-3 \text { (joints); } 10->40 \mathrm{~m} \\
\quad(\text { faults })\end{array}$ & $\begin{array}{l}\text { Tight to } \\
\text { v.narrow }\end{array}$ & $\begin{array}{l}\mathrm{n} / \mathrm{a}, \text { surface staining } \\
\text { or calcite/gypsum }\end{array}$ & $\begin{array}{l}\text { Smooth to rough } \\
\text { (joints); rough to } \\
\text { defined ridges } \\
\text { (faults) }\end{array}$ & Dry \\
\hline
\end{tabular}

Table 12 Moisture content results

\begin{tabular}{|c|c|c|c|c|c|c|}
\hline \multirow[t]{2}{*}{ Locality } & \multirow[t]{2}{*}{ Lithology } & \multirow[t]{2}{*}{ Member } & \multirow[t]{2}{*}{ Count } & \multicolumn{3}{|c|}{$\mathrm{MC}(\%)$} \\
\hline & & & & Min & Max & Mean \\
\hline 1 & Lmst & $\mathrm{PO}$ & 2 & 0.66 & 0.71 & 0.68 \\
\hline 1 & Mdst & $\mathrm{PO}$ & 1 & $\mathrm{n} / \mathrm{a}$ & $\mathrm{n} / \mathrm{a}$ & 1.08 \\
\hline 2 & Lmst & STM & 1 & $\mathrm{n} / \mathrm{a}$ & $\mathrm{n} / \mathrm{a}$ & 0.45 \\
\hline 2 & Mdst & STM & 1 & $\mathrm{n} / \mathrm{a}$ & $\mathrm{n} / \mathrm{a}$ & 1.52 \\
\hline 3 & Lmst & SS & 3 & 0.42 & 0.68 & 0.58 \\
\hline
\end{tabular}

Table 13 UCS test results

\begin{tabular}{|c|c|c|c|c|c|}
\hline Locality & Member & Description & $\mathrm{MC}(\%)$ & $\mathrm{MC}(\%)$ & $\begin{array}{l}\text { UCS (MPa) } \\
\text { Mean [Range] }\end{array}$ \\
\hline 1 & $\mathrm{PO}$ & Very strong light grey LIMESTONE & 0.7 & 6 & $\begin{array}{l}122 \\
{[88-152]}\end{array}$ \\
\hline 2 & STM & Very strong to strong light grey LIMESTONE & 0.5 & 1 & 85 \\
\hline 3 & SS & Strong medium grey argillaceous LIMESTONE & 0.6 & 1 & 56 \\
\hline 1 & PO & Medium strong dark grey MUDSTONE & 1.1 & 1 & 53 \\
\hline
\end{tabular}


Table 14 Point load test results

Results for limestone

\begin{tabular}{|c|c|c|c|c|c|c|c|c|c|}
\hline Locality & Member & $\mathrm{MC}(\%)$ & \multicolumn{2}{|c|}{ Count } & \multicolumn{3}{|c|}{ Mean $\mathrm{I}_{\mathrm{S}(50)}$} & \multicolumn{2}{|c|}{ UCS (MPa) mean [Range] } \\
\hline 1 & $\mathrm{PO}$ & 0.7 & \multicolumn{2}{|c|}{17} & \multicolumn{3}{|c|}{5.45} & \multicolumn{2}{|c|}{$120[73-169]$} \\
\hline 2 & STM & 0.5 & \multicolumn{2}{|l|}{4} & \multicolumn{3}{|l|}{4.17} & \multicolumn{2}{|c|}{$92[80-104]$} \\
\hline 3 & SS & 0.6 & \multicolumn{2}{|l|}{15} & \multicolumn{3}{|l|}{3.34} & \multicolumn{2}{|c|}{$73[39-101]$} \\
\hline \multicolumn{10}{|c|}{ Results for mudstone } \\
\hline \multirow[t]{2}{*}{ Locality } & \multirow[t]{2}{*}{ Member } & \multirow[t]{2}{*}{$\mathrm{MC}(\%)$} & \multicolumn{2}{|c|}{ Count [Invalid] } & \multicolumn{2}{|c|}{ Mean $\mathrm{I}_{\mathrm{S}(50)}$} & Mean $\mathrm{I}_{\mathrm{A}(50)}$ & \multicolumn{2}{|c|}{ UCS (MPa) Mean [Range] } \\
\hline & & & $--\mathrm{I}$ & II & $--\mathrm{I}$ & II & & $--\mathrm{I}$ & II \\
\hline \multirow[t]{2}{*}{1} & \multirow[t]{2}{*}{ PO } & \multirow[t]{2}{*}{1.1} & 14 & 7 & \multirow[t]{2}{*}{2.92} & \multirow[t]{2}{*}{1.52} & \multirow[t]{2}{*}{1.92} & 64 & 33 \\
\hline & & & [3] & [1] & & & & {$[33-83]$} & [7-54] \\
\hline \multirow[t]{2}{*}{2} & \multirow[t]{2}{*}{ STM } & \multirow[t]{2}{*}{1.5} & 16 & 9 & \multirow[t]{2}{*}{2.09} & \multirow[t]{2}{*}{1.32} & \multirow[t]{2}{*}{1.58} & 46 & 29 \\
\hline & & & [4] & & & & & [13-88] & [4-46] \\
\hline 3 & SS & - & 1 & - & 2.03 & - & - & 45 & - \\
\hline
\end{tabular}

where: II and -I denote parallel and perpendicular (orientation) respectively

Table 15 Brazilian test results

\begin{tabular}{|c|c|c|c|c|c|c|c|}
\hline \multicolumn{8}{|c|}{ Results for Limestone } \\
\hline Locality & Member & $\mathrm{MC}(\%)$ & Count & \multicolumn{4}{|c|}{ BTS (MPa) mean [Range] } \\
\hline 1 & $\mathrm{PO}$ & 0.7 & 4 & \multicolumn{4}{|c|}{$12.6[11.5-14.6]$} \\
\hline 2 & STM & 0.5 & 5 & \multicolumn{4}{|c|}{$11.5[10.1-13.4]$} \\
\hline 3 & SS & 0.6 & 3 & \multicolumn{4}{|c|}{10.13 [9.17-10.89] } \\
\hline \multicolumn{8}{|c|}{ Results for mudstone } \\
\hline Locality & Member & $\mathrm{MC}(\%)$ & $\begin{array}{l}\text { Count } \\
--I\end{array}$ & II & $\begin{array}{l}\text { BTS (MPa) } \\
--\mathrm{I}\end{array}$ & $\begin{array}{l}\text { mean [Range] } \\
\text { II }\end{array}$ & AI (Anisotropic Index) \\
\hline 1 & $\mathrm{PO}$ & 1.1 & 4 & 2 & $6.41[4.11-7.75]$ & $6.89[6.59-7.20]$ & $1.1 ?$ \\
\hline 2 & STM & 1.5 & 1 & 1 & 5.97 & 3.52 & 1.7 \\
\hline
\end{tabular}

where: II and -I denote parallel and perpendicular (orientation) respectively

Table 16 CERCHAR test results

\section{CERCHAR abrasivity test results}

\begin{tabular}{lllllllll}
\hline Member & Locality & Lithology & Member & Count & Mean pin wear (div) & Mean CAI (-) & STDEV (-) & Classification \\
\hline PO & 1 & Lmst & PO & 1 & 90 & 1.8 & 0.22 & Low \\
STM & 2 & Lmst & STM & 1 & 83 & 1.6 & 0.91 & Low \\
SS & 3 & Lmst & SS & 1 & 42 & 0.8 & 0.45 & Very low \\
PO & 1 & Mdst & PO & 1 & 17 & 0.4 & 0.09 & 0.05 \\
STM & 2 & Mdst & STM (--I) & 1 & 23 & 0.4 & 0.83 & Extremely low \\
SS & 2 & Mdst & STM (II) & 1 & 22 & & Extremely low low \\
\hline
\end{tabular}




\section{Justification}

- PO and STM members have similar proportions of limestone $(\sim 50 \%)$, bed thicknesses and rock mass classifications, therefore these are grouped to form GT2. The main discrepancy is that the STM member appears weaker; however, this is not statistically significant.

- Glen et al. (2005) define Pz-Somerset as the most competent with $20-52 \%$ limestone; therefore, this geological unit may be GT2 (or GT3).

- SS member (or Bz-Somerset) has a lower limestone percentage (4-32\%). Bed thicknesses (particularly mudstone) are larger and the GSI-values lower therefore, assigned GT3. Additionally, the UCS is lower but still within error of the PO and STM members.

- The Az-Somerset is preliminarily assigned to GT3, based on geological descriptions from Glen et al. (2005) and limestone percentages from literature.

- The LVN member is mostly comprised of shale, with limestone proportions of $0-15 \%$. From the field rock description, the mudstone/shale is also considered to be weaker.

- Lz-Somerset preliminarily assigned to GT4, based on high proportions of shale/mudstone (72-100\%).

Acknowledgements The authors would like to acknowledge Mr D. Brown, Mr. K. Handley, Dr. R. Fowell, Mr. R. Slocombe, Mr. H. Holmes, Mr. F. Greig, Mr. Peter Gilbert and Mr. Tom Berry.

Open Access This article is licensed under a Creative Commons Attribution 4.0 International License, which permits use, sharing, adaptation, distribution and reproduction in any medium or format, as long as you give appropriate credit to the original author(s) and the source, provide a link to the Creative Commons licence, and indicate if changes were made. The images or other third party material in this article are included in the article's Creative Commons licence, unless indicated otherwise in a credit line to the material. If material is not included in the article's Creative Commons licence and your intended use is not permitted by statutory regulation or exceeds the permitted use, you will need to obtain permission directly from the copyright holder. To view a copy of this licence, visit http://creativecommons.org/licenses/by/4.0/.

\section{References}

Alber M (1996) Prediction of penetration and utilization for hard rock TBMs. In Proc of the ISRM International Symposium - EUROCK 96, Turin - Italy, September 1996. ISRM-EUROCK-1996-090

Alber M (2000) Advance rates of hard rock TBMs and their effects on project economics. Tunn Undergr Sp Tech 15(1):55-64

Alber M, Yarali O, Dahl F, Bruland A, Kasling H, Michalakopoulos TN, Cardu M, Hagan P, Aydin H, Ozarslan A (2014) ISRM suggested method for determining the abrasivity of rock by the cerchar abrasivity test. Rock Mech Rock Eng 47(1):261-266

Anagnostou G, Kovári K (1996) Face stability conditions with earthpressure-balanced shields. Tunn Undergr Sp Tech 11(2):165-173
Aydin A (2009) ISRM suggested method for determination of the Schmidt hammer rebound hardness: revised version. Int J Rock Mech Min Sci 46(3):627-634

Barton N (1999) TBM performance estimation in rock using QTBM. Tunnels \& Tunnelling, September, pp. 30-34

Barton N (2000) TBM tunnelling in jointed and faulted rock. Taylor and Francis, London

Barton N (2014) Optimum advance for long distance TBM drives. Tunneltalk. January

Barton N, Lien R, Lunde J (1974) Engineering classification of rock masses for the design of tunnel support. Rock Mech 6(4):189-236

Benardos A, Paraskevopoulou C, Diederichs M (2013) Assessing and benchmarking the construction cost of tunnels. In: Proceedings of 66th Canadian Geotechnical Conference, GeoMontreal on Geoscience for Sustainability, September 29 - October 3, 2013, Montreal, Canada

BGS (2019) The BGS lexicon of named rock units. Available from: https://www.bgs.ac.uk/lexicon/lexicon.cfm?pub=BLI. Accessed 15 July

Bieniawski ZT (1973) Engineering classification of jointed rock masses. Int J Rock Mech Min Sci 15(12)

Bilgin N, Copur H, Balci C (2014) Mechanical excavation in mining and civil industries. CRC Press

Bing Maps (2019) Maps. Available from: https://www.bing.com/maps.

Brook N (1985) The equivalent core diameter method of size and shape correction in point load testing. Int J Rock Mech Min Sci 22(2):6170

Cox B, Sumbler M, Ivimey-Cook H (1999) A formational framework for the Lower Jurassic of England and Wales (onshore area). Keyworth, Nottingham, British Geological Survey, 25pp. (RR/99/001)

Deere DU, Deere DW (1988) The RQD index in practice. Rock Classif Syst Eng Purpose:91-101

Deere D, Miller R (1966) Engineering classification and index properties for intact rock. Geology. https://doi.org/10.21236/ad0646610

Diederichs MS (2020) Challenges in Tunnelling Through Layered Rockmasses. In Proc of the ISRM International Symposium EUROCK 2020, physical event not held, June 2020. ISRMEUROCK-2020-033

Farmer IW, Glossop NH (1980) Mechanics of disc cutter penetration. T\&TI. 12(6):22-25

Farrokh E (2013) Study of utilization factor and advance rate of hard rock TBMs. Dissertation, Pennsylvania State University.

Farrokh E, Rostami J, Laughton C (2012) Study of various models for estimation of penetration rate of hard rock TBMs. Tunn Undergr Sp Tech 30:110-123

Flint DE, Corwin G, Dings MG, Fuller WP, Macneil FS, Saplis RA (1953) Limestone walls of Okinawa. GSA Bull 64(11):1247-1260

Glen RA, Hancock PL, Whittaker A (2005) Basin inversion by distributed deformation: the southern margin of the Bristol Channel Basin, England. J Struct Geol 27(12):2113-2134

Gong QM, Zhao J (2009) Development of a rock mass characteristics model for TBM penetration rate prediction. Int J Rock Mech Min Sci 46(1):8-18

Hassanpour J, Rostami J, Khamehchiyan M, Bruland A (2009) Developing new equations for TBM performance prediction in carbonate-argillaceous rocks: a case history of Nowsood water conveyance tunnel. Geomech Eng 4(4):287-297

Hassanpour J, Ghaedi Vanani AA, Rostami J, Cheshomi A (2016) Evaluation of common TBM performance prediction models based on field data from the second lot of Zagros water conveyance tunnel. Tunn Undergr Sp Tech 52:147-156

Hobbs PRN, Entwisle DC, Northmore, KJ, Sumbler MG, Jones LD, Kemp S, Self S, Barron M, Meakin JL (2012) Engineering Geology of British Rocks and Soils-Lias Group. BGS Internal Report OR/12/032, pages 323 
Hoek E, Wood D, Shah S (1992) A modified Hoek-Brown criterion for jointed rock masses. Rock Characterization: ISRM Symposium, Eurock '92, Chester, UK, 14-17 September 1992. January 1992, 209-214

ISRM (2007) The Complete ISRM Suggested Methods For Rock Characterisation, Testing and Monitoring: (eds.) Ulusay, R. and Hudson, J. 1974-2006.

Marinos V (2019) A revised, geotechnical classification GSI system for tectonically disturbed heterogeneous rock masses, such as flysch. B Eng Geol Environ 78(2):899-912

Marinos P, Hoek E (2001) Estimating the geotechnical properties of heterogeneous rock masses such as flysch. B Eng Geol Environ 60(2):85-92

Marinos V, Marinos P, Hoek E (2005) The geological strength index: Applications and limitations. B Eng Geol Environ 64(1):55-65

Marinos V, Goricki A, Malandrakis E (2019) Determining the principles of tunnel support based on the engineering geological behaviour types: example of a tunnel in tectonically disturbed heterogeneous rock in Serbia. B Eng Geol Environ 78(4):2887-2902

Nelson PP (1983) Tunnel boring machine performance in sedimentary rock. Cornell University

Palmström A (2001) In-Situ Characterization of Rocks. A.A BALKEMA

Paraskevopoulou C, Benardos A (2012) Construction cost estimation for Greek road tunnels in relation to the geotechnical conditions. In: Proc. Int. Symp. Practices and trends for financing and contracting tunnels and underground works (Tunnel Contracts 2012), March 2012, Athens

Paraskevopoulou C, Benardos A (2013) Assessing the construction cost of tunnel projects. Tunn Undergr Space Technol J 38(2013):497505. https://doi.org/10.1016/j.tust.2013.08.005

Paraskevopoulou C, Boutsis G (2020) Cost overruns in tunnelling projects: investigating the impact of geological and geotechnical uncertainty using case studies. Special Issue Underground Infrastructure Engineering of Infrastructure Journal (MDPI). Infrastructures 5(9): 73. https://doi.org/10.3390/infrastructures5090073

Paraskevopoulou C, Skolidis A, Marinos V, Parsons S (in press) Integrating uncertainty into geotechnical design of underground space using a probabilistic approach: the case of Egnatia Odos Highway. Revised paper Submitted to: Tunnelling and Underground Space Technology Journal.

Romana M, Vasarhelyi B (2007) A discussion on the decrease of unconfined compressive strength between saturated and dry rock samples

Rostami J, Ozdemir L (1993) New model for performance production of hard rock TBMs. Proc, RETC

Rostami J, Ghasemi A, Alavi Gharahbagh E, Dogruoz C, Dahl F (2014) Study of dominant factors affecting cerchar abrasivity index. Rock Mech Rock Eng 47(5):1905-1919
Royal Haskoning (2009) 14 Groundwater and Geology Review HPC Power Station. https://www.edfenergy.com/sites/default/files/V2\% 20C14\%20Groundwater\%20and\%20Geology.pdf. Assessed 20 June 2019

Sapigni M, Berti M, Bethaz E, Busillo A, Cardone G (2002) TBM performance estimation using rock mass classifications. Int J Rock Mech Min Sci 39(6):771-788

Sattler T, Paraskevopoulou C (2019) Implications on characterizing the extremely weak Sherwood Sandstone: case of slope stability analysis using SRF at Two Oak Quarry in the UK. Geotech Geol Eng 37: 1897-1918. https://doi.org/10.1007/s10706-018-0732-3

Sheppard TH, Houghton RD, Swan AR (2006) Bedding and pseudobedding in the Early Jurassic of Glamorgan: deposition and diagenesis of the Blue Lias in South Wales. Proc PGA 117(3):249-264

Simms M, Chidlaw M, Morton N, Page K (2004) British Lower Jurassic Stratigraphy. Geol Conserv Rev Ser 30:458

Skolidis A, Paraskevopoulou C, Marinos V, Parsons S (2020) Accounting for uncertainty in geotechnical design using a probabilistic approach. In: Proceedings of WTC 2020, Word Tunnelling Congress on Innovation and Sustainable Underground Serving Global Connectivity, September 2020, Kuala Lumpur, Malaysia

Tarkoy PJ (2009) Simple and practical TBM performance prediction. Geomech Tunn 2(2):128-139

Ulusay R, Hudson J (eds.) (2007) The complete ISRM suggested methods for rock characterisation, testing and monitoring: 19742006.

Vallejo L, Welsh R, Robinson M (1989) Correlation Between Unconfined Compressive and Point Load Strengths For Appalachian Rocks. The 30th U.S. Symposium on Rock Mechanics (USRMS), June 19-22. ARMA-89-0461

Vergara IM, Saroglou C (2017) Prediction of TBM performance in mixed-face ground conditions. Tunn Undergr Sp Tech 69:116-124

Whittaker A, Green G (1983) Geology of the country around Westonsuper-Mare. Memoir of the geological survey of Great Britain, HMSO, London

Yau K, Paraskevopoulou C, Konstantis S (2019) A probabilistic approach to assess the risk of liner instability when tunnelling through karst geology using geotechnical baseline reports. In: Proceedings of WTC 2019, Word Tunnelling Congress on Tunnels and Underground Cities: Engineering and Innovation meet Archaeology, Architecture and Art, May 2019, Naples, Italy, Eds. Peila, Viggiani, Celestino, Taylor \& Francis Group

Yau K, Paraskevopoulou C, Konstantis S (2020) Spatial variability of karst and effect on tunnel lining and water inflow. A probabilistic approach. Tunn Undergr Space Technol J 97(2020):103248, 13 pages. https://doi.org/10.1016/j.tust.2019.103248 